\title{
Context matters: How internal and external factors impact servitization
}

\author{
Jekaterina Dmitrijeva, Andreas Schroeder, Ali Ziaee Bigdeli* and Tim Baines \\ The Advanced Services Group, Aston Business School, Aston University, Birmingham, \\ United Kingdom
}

\begin{abstract}
The study investigates how internal and external context factors impact a manufacturer's servitization process (i.e. the strategic transformation from competing through products towards competing through services). A theoretical framework was developed that integrates a multi-stage conceptualisation of servitization with a focus on the wide range of internal and external context factors that support or oppose the transformation. The study draws on the collective experiences of 25 senior executives from 17 servitizing small- and medium-sized manufacturers, using a focus group-based enquiry method. The findings recognise servitization as a multi-stage transformation process with each stage being exposed to different context factors. The findings identify a wide range of context factors and show how their specific impact varies depending on the manufacturer's servitization stage. Several theoretical and practical implications are provided.
\end{abstract}

Keywords: servitization; transformation; organisational change; organisational context

\section{Acknowledgement}

This work was supported by the European Union's Horizon 2020 research and innovation programme under the Marie Skłodowska-Curie grant agreement No 721909, and the UK's Economic and Social Research Council (ESRC) grant Ref ES/P010148/1 'Pathways towards Servitization: A trans-national study of Organisational Transformation.

* Corresponding author. Email: bigdelia@aston.ac.uk 


\section{Introduction}

Traditional manufacturers are increasingly shifting from a product-oriented to a serviceoriented focus, a strategic repositioning termed 'servitization' (Kowalkowski et al., 2017, Raddats et al., 2016). For manufacturers, servitization represents a fundamental organisational transformation (Kowalkowski et al., 2017, Baines et al., 2009a) that involves integrating services into product offerings ('service infusion', Forkmann et al. (2017)) but also changes to management processes and arrangements ('service transition', Oliva and Kallenberg (2003)). Such transformation entails changes in revenue models (Rapaccini, 2015), sales processes (Visnjic Kastalli and Van Looy, 2013), product design (Kohtamäki et al., 2013a) and risk management (Reim et al., 2016). Despite the extensive related research, we know little about the circumstances and the associated courses of action that define the transformation (Baines et al., 2017). The success of such a transformation not only depends on the manufacturer's ability to leverage its capabilities and resources ('internal context') but also on the ability to navigate its market and industry setting ('external context') (Parida et al., 2014). To orchestrate its transformation efforts effectively, the manufacturer needs to recognise the range and implications of these context factors (Tushman and Anderson, 1986).

Servitization research has already started to consider the impact of different internal and external context factors on the manufacturer's transformation. Illustrative studies examine how internal context factors, such as a manufacturer's project management capability (Baines and Shi, 2015) or value visualisation capability (Coreynen et al., 2017), impact the company's servitization progress. Regarding external factors, Finne et al. (2013) establish how external context factors, such as changing regulations, can hamper a manufacturer's servitization progress, while changes in market structures and product technologies can accelerate it.

However, researchers seem mostly to investigate context factors in isolation, despite emerging evidence pointing to the complexities a manufacturer faces in the process of servitization. Notable exceptions include Turunen and Finne (2014) who investigate the composite impact that external (i.e. competitor actions) and internal context factors (i.e. available resources, employed technologies, internal political conditions) have on the manufacturer's servitization effort. Bustinza et al. (2018) explore industry type and the kinds of services as context factors to explain the relationships between product-service innovation and firm performance. Considering the variety of different context factors that may impact a manufacturer's 
transformation, individually and combined, it is critical to develop a holistic understanding of these as a basis to conceptualise the servitization effort.

Equally important to understanding the context factors involved in the manufacturer's transformation is understanding the processual nature of the transformation itself. Complex transformations often unfold in multiple stages where different underlying objectives, activities and concerns are maintained (Van de Ven and Poole, 1995, Pettigrew, 1987). A focus on its processual nature directly challenges the servitization literature which largely conceptualises a manufacturer's servitization as a discrete strategic decision (Baines et al., 2019, Martinez et al., 2017, Kindström, 2010, Gebauer et al., 2006). Gebauer (2008), for example, presents the service offering as part of corporate strategy and develops four service strategies manufacturers can follow. Conceptualising servitization as a multi-stage process implies, however, that servitization-related activities and strategic intent may differ significantly as manufacturers progress with their transformation.

Recent servitization publications have started to propose such multi-stage models highlighting how manufacturers change priorities at different transformation stages (Kowalkowski and Ulaga, 2017, Martinez et al., 2017, Ziaee Bigdeli and Baines, 2017). Kowalkowski and Ulaga (2017), for example, differentiate between 12 transformation stages, where, in the initial stage, the foundational rationale for pursuing services is established and, in the final stage, the focus is put on structural alignment and partner management. Rabetino et al. (2016) use strategy maps to explore key practices across various transformation stages capturing the manufacturers' internal efforts.

Although research actively develops these process and context perspectives on servitization, an understanding of the interaction between these two perspectives is still missing. Exploring the distinct impacts of the different context factors at different stages of transformation provides a promising new research avenue to create a better understanding of the circumstances and associated courses of action that characterise the manufacturer's transformation. To advance this new research avenue the present study integrates a multi-stage process perspective on servitization with a focus on the internal and external context factors that impact the transformation. This conceptual integration raises the following research question: How does the organisational context influence the manufacturer's servitization across its various transformation stages? 
To answer this research question, the study draws on established organisational transformation literature (Pettigrew, 2012) and a servitization-focused transformation model (Ziaee Bigdeli and Baines, 2017). The model is used to theorise the transformation stages and analyse the data from 17 small- and medium-sized manufacturers actively pursuing servitization. Data from small- and medium-sized manufacturers is used as larger organisations often influence their internal and external contexts to fit their objectives (e.g. through capability acquisition or spinoffs) making it difficult to identify contextual impact (Helfat and Lieberman, 2002, Pearce et al., 1982). The findings identify a range of specific context factors impacting the manufacturer's servitization and demonstrate how these factors differ depending on its stage of transformation. They challenge common depictions of the difficulties the servitizing manufacturer faces and highlight the urgency of developing guidelines that take the processual and contextual nature of servitization into consideration.

The rest of the paper is structured as follows. The next section reviews the relevant theory and literature to create a sound conceptual model depicting the transformation stages and relevant context factors of servitizing manufacturers. Then, the research method is introduced and the empirical analysis and findings are outlined. The paper is concluded with a discussion on the diverse theoretical and practical implications of integrating processual and contextual perspectives of servitization.

\section{Literature review and conceptualisation}

The objective of this section is to develop a research model that holistically represents the processual and contextual dimensions that impact the servitization of a manufacturer. To develop the model, the section first theorises on the manufacturer's contextual dimensions and reviews the literature on specific factors that may impact its servitization effort before reviewing the processual dimensions that are highlighted in the literature.

\subsection{Servitization context}

Theorising the role of 'context' in servitization requires a careful deliberation of the context notion in organisational transformation theory. Pettigrew's $(1985,1987)$ foundational work on organisational transformation identifies how the changes organisations go through are affected by internal and external context factors. The external context hereby captures the political, economic, social and competitive factors that impact a transformation, whereas the internal context focuses on the factors related to organisational structure, internal politics and corporate 
culture (Pettigrew, 1985, Pfeifer and Salancik, 1978, Hannan and Freeman, 1977, Meyer and Rowan, 1977). Pettigrew's focus on the internal and external context highlights an 'adaptive perspective' on the organisation-context interaction (Frishammar, 2006), which has been used to explore factors impacting transformations among a diversity of large and, widely, small companies (e.g. Ates and Bititci, 2011, Barnes, 2002, Hudson et al., 2001). Organisations are impacted by context factors because they influence its manager's effort to adapt the organisation to these particular contextual demands (through strategy formulation and implementation).

Servitization research regularly adopts such an adaptive perspective with studies exploring, for example, how market conditions (Valtakoski and Witell, 2018, Gebauer, 2008) or aspects of the existing service network (Alghisi and Saccani, 2015) impact the manufacturer's choice of servitization strategy. Yet, studies following an adaptive perspective not only explore how different context factors impact an organisation's transformation but also point to the value of considering these factors together, as they do not necessarily affect the organisational transformation in isolation. As an example, Van de Ven and Poole (1995) demonstrate that the impact of a new technology (external factor) on an organisation's transformation may be mediated by its rules and programmes (internal factors). Conversely, the impact of internal context factors (e.g. a leader's ability to form strategies) on an organisation may be affected by external context factors (e.g. customer and competitor information flows) (Daft et al., 1988).

Although the servitization research already acknowledges a variety of context factors that may affect the manufacturer's transformation journey, a more holistic and integrative perspective (such as Pettigrew's $(1985,1987)$ ) needs to be considered to capture an even wider range of internal and external context factors. With servitization representing a confluence of technical, structural, organisational and commercial changes (Kowalkowski et al., 2017), it is critical to broaden further the range of context dimensions when examining the challenges a manufacturer faces in its transformation.

To shed light on the context in which a manufacturer's servitization takes place, Ziaee Bigdeli and Baines (2017) and later on Baines et al., (2019) explicitly draw on Pettigrew's perspective to conceptualise their transformation model. Although not yet applied in an empirical setting, the model proposes specific internal and external context dimensions that impact a manufacturer's servitization (Section 2.2 further outlines the transformation stages proposed in this model). The present study draws on these dimensions and adapts them to conceptualise the 
transformation context specific to small- and medium-sized manufacturers examined in this study.

In their model the manufacturer's internal context is represented by the maturity and capability dimensions. 'Organisational maturity' captures the sophistication of the manufacturer's generic management practices with their impact on its servitization (Ziaee Bigdeli and Baines, 2017). These practices include, for example, the manufacturer ability assessing its transformation progress and making informed decisions about its subsequent development. 'Organisational capability' captures the servitization-specific competences a manufacturer requires as part of its transformation effort. They reflect the new capabilities a manufacturer needs to develop or acquire to design and deliver services (Alghisi and Saccani, 2015, Storbacka et al., 2013).

The external organisational context is represented by the 'market', 'ecosystem' and 'technology' dimensions. The 'market' dimension captures the economic environment in which the manufacturer and its operations are embedded. It encompasses the market features and the customers' actions that have the power to influence the development of the manufacturer's service business (Turunen and Finne, 2014). The original model uses the term 'market pull' but the present research adapted it as 'market dimension' to better capture the underlying scope. The 'ecosystem' dimension captures the manufacturer's positioning in the value chain. It is concerned with the manufacturer's relationship with its partners as they become progressively more involved in the service value creation and delivery processes (Storbacka et al., 2013, Kohtamäki et al., 2013b). The 'technology' dimension captures the emerging tools, processes and functionalities that could impact servitization. These range from the emergence of new digital technologies to the capabilities needed to use these within the servitization context (Coreynen et al., 2017, Opresnik and Taisch, 2015).

\subsubsection{Illustrating the context dimensions}

Although the context dimensions identified above offer a framework to map out the manufacturer's transformation context, they are not yet focused on the specific servitization challenges. To apply the framework to the selected research domain, the literature review now focuses on the servitization literature in order to identify the range of themes that illustrate the servitization-specific context challenges. It takes the form of a theoretical review which emphasises the inductive identification of higher order theoretical structures and concepts, as opposed to mapping out of the full range of possible contributions from existing studies (Paré 
et al., 2015). Hence, the servitization literature is used to build on the context dimensions provided by Ziaee Bigdeli and Baines' (2017) model, making them more applicable to the empirical setting of the current study.

In order to identify the servitization-related themes that characterise the generic context dimensions, the research team reviewed a wide range of servitization studies, identified pertinent factors that were considered with their impact on servitization progress, and inductively consolidated these factors into themes based on their thematic overlaps. To ensure that the illustrated model remained sufficiently manageable and could support the exploration of these context dimensions in the current study, the number of themes was limited to five per context dimension (based on pertinence). For each dimension, the identified themes are presented with the sources and an illustration of the servitization implications discussed.

\subsubsection{Maturity dimension}

The literature review identified several contributions describing how a manufacturer's servitization progress is affected by its 'organisational maturity' (i.e. the sophistication of the manufacturer's management practices (Ziaee Bigdeli and Baines, 2017)). Table 1 lists a range of organisational maturity themes consolidated from the literature review.

Table 1. Organisational maturity dimension themes

\begin{tabular}{|l|l|}
$\begin{array}{l}\text { 'Organisational } \\
\text { maturity' themes }\end{array}$ & \multicolumn{1}{l|}{ Impact on the manufacturer's servitization } \\
\hline Leadership & $\begin{array}{l}\text { - Leadership expertise impacts the manufacturer's ability to set priorities for } \\
\text { routes to pursue service growth (Kowalkowski et al., 2017); } \\
\text { - Leadership agility facilitates servitization progress while withstanding market } \\
\text { competition (Kowalkowski et al., 2017). }\end{array}$ \\
\hline Organisational culture & $\begin{array}{l}\text { - Strong organisational service culture helps create internal buy-in for } \\
\text { servitization (Alghisi and Saccani, 2015, Lienert, 2015, Martinez et al., 2010, } \\
\text { Johnstone et al., 2009, Gebauer et al., 2005). }\end{array}$ \\
\hline Power and politics & $\begin{array}{l}\text { - Internal political climate and power distribution impact the organisational } \\
\text { realignment between product and service divisions (Burton et al., 2017). }\end{array}$ \\
\hline $\begin{array}{l}\text { Operational and strategic } \\
\text { alignment }\end{array}$ & $\begin{array}{l}\text { - Readiness to operationalise new strategies helps with product-service } \\
\text { integration (Gebauer et al., 2012a); } \\
\text { - Employees' skills and ability to translate policies into practices facilitate shift } \\
\text { towards service focus (Raja et al., 2010, Gebauer et al., 2005). }\end{array}$ \\
\hline Change acceptance & $\begin{array}{l}\text { - Visible top management commitment boosts service awareness and facilitates } \\
\text { service business investment (Alghisi and Saccani, 2015). }\end{array}$ \\
\hline
\end{tabular}

\subsubsection{Capability dimension}

Table 2 highlights the themes identified in the literature review describing how aspects of the manufacturer's servitization progress are impacted by its 'organisational capability' (i.e. the 
servitization-specific competences a manufacturer requires as part of its transformation effort (Ziaee Bigdeli and Baines, 2017)).

Table 2. Organisational capability dimension themes

\begin{tabular}{l|l|}
$\begin{array}{l}\text { 'Organisational } \\
\text { capability' themes }\end{array}$ & $\begin{array}{l}\text { Impact on the manufacturer's servitization } \\
\text { capabilities }\end{array}$ \\
\hline $\begin{array}{l}\text { Service development } \\
\text { - Service design and customer interface capabilities (Alghisi and Saccani, 2015), } \\
\text { service operations capabilities (Windahl and Lakemond, 2010), network } \\
\text { management capabilities (Parida et al., 2014) and service pricing capabilities } \\
\text { (Rapaccini, 2015) facilitate the servitization progress. }\end{array}$ \\
\hline $\begin{array}{l}\text { Product-focused } \\
\text { capabilities }\end{array}$ & $\begin{array}{l}\text { - Availability of resources (e.g. a product sales force and distribution network or } \\
\text { a field service organisation (Ulaga and Reinartz, 2011), within or outside of the } \\
\text { organisation (Paiola et al., 2013)) facilitates the transformation. }\end{array}$ \\
\hline Learning capabilities & $\begin{array}{l}\text { - Education and encouragement for understanding customer benefits from } \\
\text { services (Gebauer and Friedli, 2005) facilitate service piloting and sales. }\end{array}$ \\
\hline Innovation capabilities & $\begin{array}{l}\text { - Organisational innovation capability facilitates innovation of service business } \\
\text { models and customer processes (Visnjic et al., 2016). }\end{array}$ \\
\hline Complexity management & $\begin{array}{l}\text { - Clear goal setting and performance criteria development reduce staff concerns } \\
\text { about servitization and streamline internal processes (Ahamed et al., 2013). }\end{array}$ \\
\hline
\end{tabular}

\subsubsection{Market dimension}

The themes highlighting aspects of the 'market' dimension (i.e. the economic environment in which the manufacturer and its operations are embedded) are outlined in Table 3.

Table 3. Market dimension themes

\begin{tabular}{|c|c|}
\hline 'Market' themes & Impact on the manufacturer's servitization \\
\hline $\begin{array}{l}\text { Customers' requirements } \\
\text { and tastes }\end{array}$ & $\begin{array}{l}\text { - Shifts in market orientation towards process-oriented services create a push for } \\
\text { collaborative relationships (Bastl et al., 2012, Oliva et al., 2012, Oliva and } \\
\text { Kallenberg, 2003), customer willingness to outsource maintenance and services } \\
\text { (Jovanovic et al., 2016, Kowalkowski, 2011) and integrating customer resources } \\
\text { into value creation (Ng et al., 2012). }\end{array}$ \\
\hline $\begin{array}{l}\text { Economic and trading } \\
\text { conditions }\end{array}$ & - High level of economic development facilitates servitization (Neely, 2008). \\
\hline Customer relationships & $\begin{array}{l}\text { - Customers' satisfaction, relationship, loyalty and retention facilitate } \\
\text { servitization (Benedettini et al., 2015). }\end{array}$ \\
\hline $\begin{array}{l}\text { Legal and regulatory } \\
\text { requirements }\end{array}$ & $\begin{array}{l}\text { - Regulatory changes can affect the manufacturing core and development of } \\
\text { product-related services (Turunen and Finne, 2014). }\end{array}$ \\
\hline Market precedence & - Existence of a predecessor facilitates servitization (Turunen and Finne, 2014). \\
\hline
\end{tabular}

\subsubsection{Ecosystem dimension}

Table 4 highlights the identified themes relating to the 'ecosystem' dimension, describing how aspects of the manufacturer's servitization progress are affected by its positioning in the value chain. 
Table 4. Organisational ecosystem dimension themes

\begin{tabular}{|l|l|}
\hline 'Ecosystem' themes & Impact on the manufacturer's servitization \\
\hline Supply chain control & $\begin{array}{l}\text { - The manufacturer's control over the supply chain can facilitate product-service } \\
\text { integration through supply chain reconfiguration (Schmenner, 2009, Johnson } \\
\text { and Mena, 2008). }\end{array}$ \\
\hline $\begin{array}{l}\text { Open knowledge } \\
\text { networks }\end{array}$ & $\begin{array}{l}\text { - Open sharing data and knowledge sharing can support the manufacturer's } \\
\text { servitization effort by enabling collaborative working and joint product } \\
\text { development between buyers and suppliers (Kamp and Parry, 2017, Story et al., } \\
\text { 2017). }\end{array}$ \\
\hline Collaboration practice & $\begin{array}{l}\text { - The degree of manufacturer and stakeholder closeness and the flexible use of } \\
\text { capabilities and resources by the manufacturer facilitate the transformation } \\
\text { (Eloranta and Turunen, 2016). }\end{array}$ \\
\hline Industry-level platforms & $\begin{array}{l}\text { - Platform approaches facilitate the transformation by providing structure for } \\
\text { managing network cooperation (Eloranta and Turunen, 2016) and by enabling } \\
\text { the manufacturer to utilise information for increased operational efficiency } \\
\text { (Cenamor et al., 2017, Chesbrough, 2011). }\end{array}$ \\
\hline $\begin{array}{l}\text { - Partner relationships within the network support the service value co-creation } \\
\text { and competition as networks (Martin et al., 2019, Story et al., 2017, Jaakkola } \\
\text { and Hakanen, 2013). }\end{array}$ \\
\hline
\end{tabular}

\subsubsection{Technology dimension}

Table 5 identifies the themes related to 'technology' that are highlighted in the literature for their servitization impact.

Table 5. Technology dimension themes

\begin{tabular}{|c|c|}
\hline 'Technology' themes & Impact on the manufacturer's servitization \\
\hline Information technology & $\begin{array}{l}\text { - IT facilitates servitization by improving the delivery of new services (e.g. } \\
\text { reaction speed for a breakdown event) (Story et al., 2017, Baines and Lightfoot, } \\
\text { 2014, Lightfoot et al., 2011). }\end{array}$ \\
\hline Product technology & $\begin{array}{l}\text { - Technology-driven design allows for the modelling of new service offers } \\
\text { (Holmström and Partanen, 2014). }\end{array}$ \\
\hline Connectivity & $\begin{array}{l}\text { - Availability of consumer data facilitates servitization by creating new channels } \\
\text { (Kowalkowski et al., 2017, Spring and Araujo, 2016) and different types of } \\
\text { service innovation (Coreynen et al., 2017, Gago and Rubalcaba, 2007). }\end{array}$ \\
\hline Sensor integration & $\begin{array}{l}\text { - The ability to collect data on the customers' goods/services experiences within a } \\
\text { specific time, setting and place (Parry et al., 2016) provides insights into service- } \\
\text { related consumer behaviour (Bustinza et al., 2013). }\end{array}$ \\
\hline Analytics & $\begin{array}{l}\text { - Visualisation and analysis techniques for big data processing facilitate the } \\
\text { establishment of new service propositions (Schroeder et al., 2019, Opresnik and } \\
\text { Taisch, 2015, Lee et al., 2014). }\end{array}$ \\
\hline
\end{tabular}

The review identified a range of themes sourced from the published literature with their impacts on the manufacturer's servitization effort which helped to specify the context perspective that Ziaee Bigdeli and Baines (2017) proposed. To continue further the conceptualisation of the manufacturer's transformation, the next section focuses on the processual perspective. 


\subsection{Servitization process}

This review section focuses on the processes a manufacturer goes through as part of its transformation towards becoming a service provider (Martinez et al., 2017, Kowalkowski and Ulaga, 2017, Brax and Visintin, 2015, Weick and Quinn, 1999). Servitization generally involves substantial changes in the objectives, structures, competencies and culture of a manufacturer (Baines et al., 2009b, Oliva and Kallenberg, 2003). Due to the fundamental transformational nature of these changes, servitization can be categorised as a 'metamorphic' transformation (Meyer et al., 1990). A metamorphic transformation characterises framebreaking transitions where organisational configurations that are held together by inertial forces are rearranged to create a better fit between the organisation and the environment (Meyer et al., 1995, Meyer et al., 1990). Metamorphic transformations generally unfold in the form of the life-cycle stages an organisation goes through as one set of objectives and activities transforms into another. Life-cycle stages suggest the existence of an underlying logic that directs and regulates an organisation's transformation; as the transformation progresses, this logic matures and becomes progressively more realised and differentiated (Van de Ven and Poole, 1995).

A number of studies have adopted a metamorphic perspective (including life-cycle stages and frame-breaking transitions) to conceptualise the manufacturer's servitization. One example is provided by the aforementioned Ziaee Bigdeli and Baines's (2017) 'organisational transformation towards servitization' model which conceptualises the transformation process along four stages (exploration, engagement, expansion, exploitation). Another stage model has been developed by Kowalkowski and Ulaga (2017) who conceptualise the manufacturer's transformation along 12 stages across four areas of strategic considerations (foundations, strategy, implementation and structure). This model is targeted at practitioners to help guide their servitization effort in the form of a roadmap for service growth. Martinez et al. (2017) have developed a model that identifies 36 steps the manufacturer goes through in the course of its service adoption, which are clustered into 12 stages. Lütjen et al. (2017) have proposed a three-stage model (service initiation, service anchoring and service extension) to map out the service transformation and associated barriers of a case company.

Although different servitization stage models have already been developed, they are not equally suitable for integrating a processual and contextual perspective on servitization - the objective of the present research. The models by Kowalkowski and Ulaga (2017) and Martinez et al. (2017), which offer 12 stages or 36 steps respectively, become unmanageable when integrated 
with a context perspective. The model by Lütjen et al. (2017), although limited to three stages, is deeply rooted in one industry sector (energy utility), which makes it less suitable for the present research domain. Ziaee Bigdeli and Baines's (2017) model with its four stages, although it has not yet been applied in an empirical setting, appears appropriate to serve as the basis for conceptualising the processual perspective of servitization.

In Ziaee Bigdeli and Baines's (2017) model, the exploration stage describes the manufacturer's initial learning about servitization and its associated implications; the stage is completed when the manufacturer is confident that a shift to a service-oriented business model represents a viable opportunity ${ }^{1}$. The subsequent engagement stage captures the manufacturer's systematic evaluation and communication of the business potential of servitization and the creation of transformation readiness throughout the organisation. The expansion stage describes the manufacturer's development of specific product-service offerings and changes in the organisational structures; these developments continue until significant value from servitization is demonstrated. The transformation culminates in the exploitation stage, where the manufacturer continuously targets the optimisation and delivery of its servitization portfolio to ensure that the service offerings provide a viable basis for competition.

It is important to note that, although the servitization stage models map out a trajectory from a product focus to a service focus, a manufacturer may not necessarily start its servitization efforts with the exploration stage, for instance. A manufacturer may have already experimented with services but may not have had the momentum to systematically engage in the transformation process. These stage models, nevertheless, lend themselves as a helpful framework to conceptualise the processual nature of servitization, providing it with a logical start and development direction.

\footnotetext{
${ }^{1}$ Ziaee Bigdeli and Baines (2017) use the terms 'exploration' and 'exploitation' to describe the two end-points of a single specific servitization venture (following Faems et al., 2012, Sharma and Salvato, 2011). The same terms are also used in the organisational-level ambidexterity discourse (March, 1991, He and Wong, 2004) which describes how an organisation that engages in various different ventures (which could be at different development stages) may be required to engage in exploration and exploitation simultaneously. The section on future research opportunities (Section 6.4) will discuss the implications of the manufacturer simultaneously engaging in two or more servitization ventures, which will also consolidate the venture-level and organisationlevel discourses for the servitization context.
} 


\subsection{Integrating processual and contextual perspectives of servitization}

The literature review suggests that a manufacturer's servitization denotes a longitudinal transformation process, encapsulating different objectives and activities across multiple stages (Kindström and Kowalkowski, 2015). Considering servitization as a longitudinal multi-stage process challenges the literature that examines the manufacturer's servitization as a discrete adoption decision (Martinez et al., 2017, Baines et al., 2017, Kindström, 2010, Gebauer et al., 2006). As the manufacturer's objectives and activities change across its transformation stages, we can also expect that the impacts of the context factors across the manufacturer's various context domains change. Integrating these perspectives provides an opportunity to develop a deeper understanding of the impact of the transformation dynamics that characterise the manufacturer's servitization efforts.

The present study facilitates the development of this deeper understanding by investigating the impacts the manufacturer's context factors create across the four transformation stages. Figure 1 outlines the resultant research framework that highlights the transformation stages and the context dimensions with their individual themes as identified in the literature review.

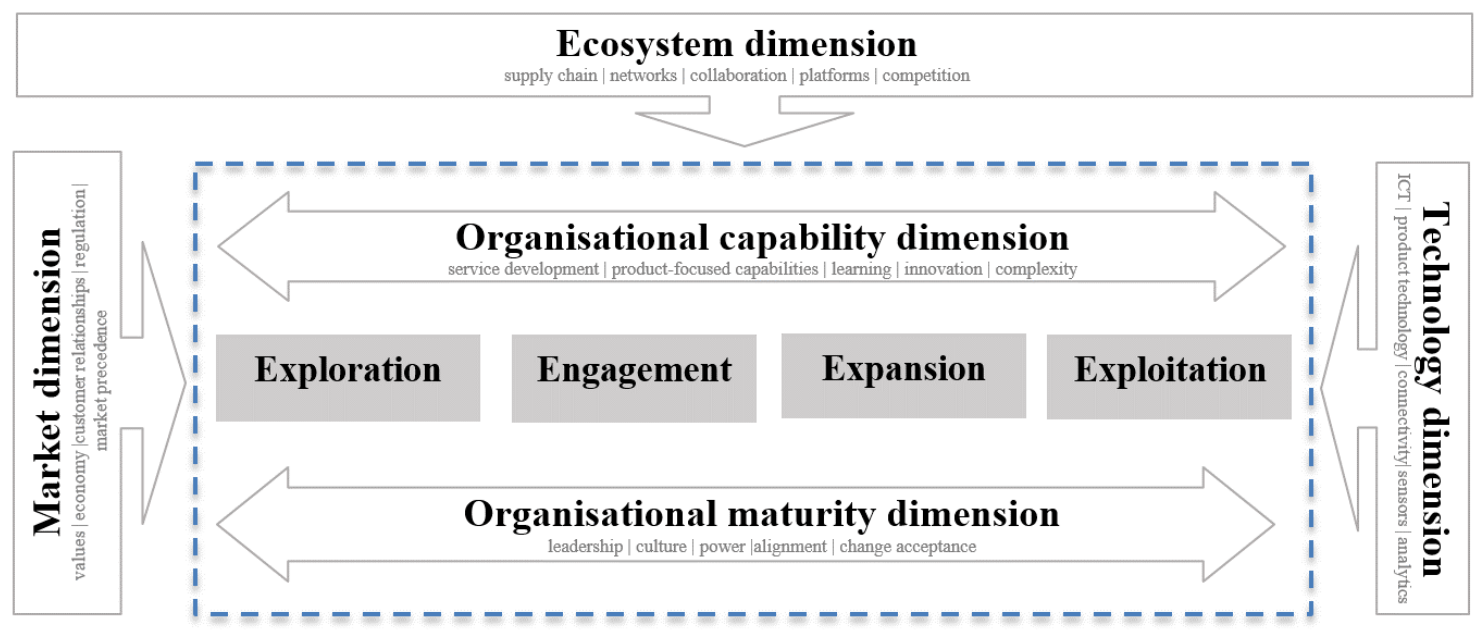

Figure 1. Theoretical framework for investigating the servitization process within the manufacturer's internal and external contexts (adapted from Ziaee Bigdeli and Baines, 2017)

The present study will focus specifically on the case of small- and medium-sized manufacturers to investigate the impacts the context factors create across their transformation. Smaller organisations are often more exposed to their environment (Pearce et al., 1982), as larger organisations can more easily influence their internal and external contexts to fit their objectives (e.g. through capability acquisition or spin-offs) (Helfat and Lieberman, 2002). Also, smaller organisations might be more pressured to transform in shorter time frames 
because of their smaller product portfolios and higher specialisations (Ceci and Masini, 2011) which may make the impact of their context factors more recognisable.

At this point, there is a limited number of servitization publications specifically investigating small- and medium-sized manufacturers. Most studies focus on a diverse range of manufacturers (Windler et al., 2017) or on multinationals (Xing et al., 2017, Bustinza et al., 2015, Visnjic Kastalli and Van Looy, 2013). Yet, despite the limited research focus, small- and medium-sized manufacturers are increasingly engaging in servitization (Ambroise, 2018, Mennens et al., 2018) and their alleged speed of transformation might imply that they are already representing a sizable cohort among servitizing manufacturers (e.g. European Comission, 2018). For this reason, this manufacturer segment is of particular interest for studying the influences of organisational context on the various transformation stages of servitization ${ }^{2}$

\section{Research method}

The investigation of the diverse impact scenarios represents a weakly defined research problem that requires an identification of the relevant impact factors and a reflection on the nature of their impact. Complex weakly defined problems are best addressed by pooling the insights and intelligence of a group of people (Moore, 1987, Parker and Tritter, 2006). The present study adapted elements of the Delphi method to a face-to-face nominal group process (Rowe and Wright, 1999, Van De Ven and Delbecq, 1971).

The conventional Delphi method focuses on three components: (1) establishing a panel of experts on an issue of concern, (2) executing and conducting a series of rounds by using written text to get expert opinions on that issue, and (3) sharing the feedback of the respondents with the participants (Hasson et al., 2000, Woudenberg, 1991, Bardecki, 1984). Face-to-face focus groups built on the Delphi method represent a productive and time-efficient setting as they incorporate a structure designed to capture and consolidate real-world expertise on complex matters with the controlled flexibility of a data collection method (Hsu and Sandford, 2007, Van de Ven and Delbecq, 1974).

\footnotetext{
${ }^{2}$ A discussion about the extent to which the SME-based findings can be generalised is provided in the Limitations section (6.3).
} 
It is recognised that the Delphi method occupies a hybrid epistemological status that bridges the divide between established constructivist and positivist research traditions (Critcher and Gladstone, 1998): on the one hand, the method seeks to elicit the insights and interpretations of experts that are directly involved in the subject of the research, while on the other hand, the method seeks to aggregate and quantify or prioritise the insights obtained. Yet, the Delphi represents a widely used method, particularly for research areas which are not yet fully developed, and where theory is not yet refined (Mullen, 2003). For example, it has been successfully used to examine the challenges organisations face in extracting value from innovation (Vidgen et al., 2017) or the challenges of future manufacturing processes (Bokrantz et al., 2017).

Within its application in these areas, the Delphi method positions expert judgement as a legitimate source of data and recognises the combination and integration of the diverse expert inputs as valid research findings. As such, the Delphi method is not necessarily a way to create consensus but 'a means of determining the extent to which a consensus exists amongst a group of people' (p.208, Xiao et al., 1997). The trustworthiness and rigour of the method lies in the ability of the panel members to expand on and revise their input in the course of several iterations and the ability of the researchers to identify a certain level of consensus to be able to judge the validity of the responses (Brady, 2015, Mitroff and Turoff, 2002).

The study followed the aforementioned Delphi guidelines but used aspects of face to face discussion and deliberation between the Delphi rounds. In particular, the first round sought to elicit individual input in smaller moderated groups followed by brief feedback and a discussion; the second round sought to capture across-group perspectives followed by feedback; the third (and final) round addressed the entire expert panel and was followed by a prioritisation session and an invitation for additional commentary.

\subsection{Establishing the expert panel}

The focus-group panel was established by selecting senior decision-makers of small- and medium-sized manufacturers. Within smaller manufacturers, servitization is generally coordinated by individuals who maintain an overview of the diverse developments and can provide comprehensive insights on contextual impacts (as opposed to larger manufacturing organisations where the servitization effort is often spread across multiple decision-makers and product domains). 
The panel formation considered the number of panellists, the level of their expertise (Baker et al., 2006) and the manufacturer's servitization advancement. Following established criteria (Baines and Shi, 2015), the panel formation included representatives who (1) are associated with a servitizing manufacturer, (2) are involved in driving the servitization effort, and (3) have knowledge of the organisation's structures and functions. The formation also included manufacturers that are at different transformation stages (from exploration to exploitation) to ensure that insightful comments about past experiences and future scenarios could be captured.

A focus group of 25 panellists $^{3}$ was formed representing 17 small- and medium-sized organisations actively engaged in servitization (see Table 6). All of the panellists had senior roles in their organisations and were tasked with driving and coordinating their company's servitization efforts. The majority of the represented organisations were traditional machine or components manufacturers, while some were product-related solution-providers (building solutions around traditional manufactured products). The range of services being considered included outcome-focused services aiming to ensure or maintain the product condition (e.g. monitoring as a service, installation as a service) as well as services where a capability is delivered based on the performance of the product (e.g. lighting as a service, optimisation as a service).

It should be noted that the majority of the organisations were still in the early stages of transformation (seven in the exploration stage and five in the engagement stage) and, therefore, their portfolios and service models had not yet been fully established. The representatives selfdeclared their transformation stages based on the criteria outlined at the beginning of the focusgroup process.

Table 6. Panel members and their organisations

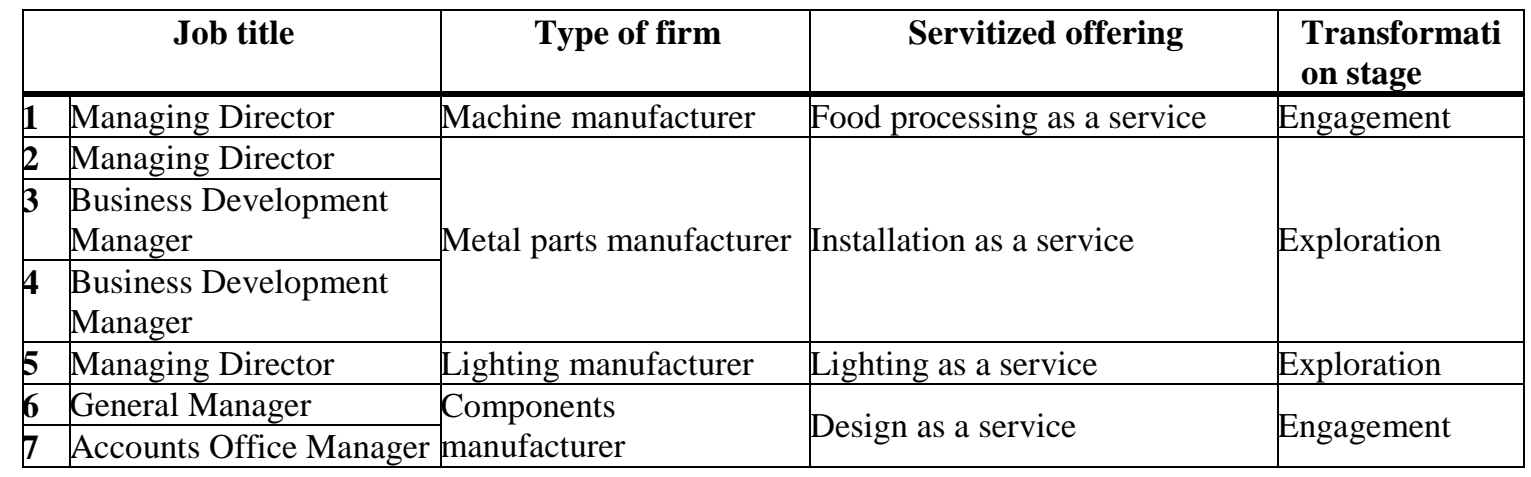

\footnotetext{
3 The literature guidance on panel sizes varies with suggestions ranging from seven or more members (Dalkey and Helmer, 1963), ten to 50 (Turoff, 1990) and up to 80 members (Rowe and Wright, 1999).
} 


\begin{tabular}{|c|c|c|c|c|}
\hline 8 & Managing Director & $\begin{array}{l}\text { Precision components } \\
\text { manufacturer }\end{array}$ & Scheduling as a service & Exploration \\
\hline 9 & General Manager & Machinery manufacturer & Optimisation as a service & Exploitation \\
\hline 10 & Managing Director & \multirow{2}{*}{ Tubing manufacturer } & \multirow{2}{*}{ Design as a service } & \multirow{2}{*}{ Exploration } \\
\hline 11 & Project Engineer & & & \\
\hline 12 & Managing Director & $\begin{array}{l}\text { Electrical equipment } \\
\text { manufacturer }\end{array}$ & Monitoring as a service & Exploration \\
\hline 14 & $\begin{array}{l}\text { Head of Business } \\
\text { Development }\end{array}$ & Packaging manufacturer & Monitoring as a service & Exploitation \\
\hline \begin{tabular}{|l|}
15 \\
16
\end{tabular} & \begin{tabular}{|l} 
Managing Director \\
Production Manager
\end{tabular} & $\begin{array}{l}\text { Components } \\
\text { manufacturer }\end{array}$ & Design as a service & Exploration \\
\hline 17 & Managing Director & $\begin{array}{l}\text { Components } \\
\text { manufacturer }\end{array}$ & Design as a service & Exploration \\
\hline 18 & Chief Executive Officer & IT solution provider & Data storage as a service & Engagement \\
\hline 19 & $\begin{array}{l}\text { Head of Marketing and } \\
\text { Operations }\end{array}$ & IT solution provider & Data storage as a service & Engagement \\
\hline 20 & Managing Director & Safety solutions provider & Safety as a service & Expansion \\
\hline 21 & Managing Director & \multirow[b]{2}{*}{ Printing solution provider } & \multirow[b]{2}{*}{ Printing as a service } & \multirow[b]{2}{*}{ Engagement } \\
\hline 22 & $\begin{array}{l}\text { Sales and Marketing } \\
\text { Director }\end{array}$ & & & \\
\hline 23 & $\begin{array}{l}\text { Head of Sales } \\
\text { Product Director }\end{array}$ & $\begin{array}{l}\text { Financial solutions } \\
\text { provider }\end{array}$ & Cash management as a service & Expansion \\
\hline 25 & Operations Director & Systems provider & Monitoring as a service & Expansion \\
\hline
\end{tabular}

\subsection{Executing the focus group}

The 25 panellists were invited to participate in a one-day researcher-led focus group process comprising three rounds. For the first round, the panellists were divided into five sub-groups of five members each to ensure ideal interaction arrangements following guidance from Van de Ven and Delbecq (1972). The panellists were introduced to the four-stage transformation model and were provided with an enquiry form to elicit the context factors that impact their transformation at each stage and explain the nature of that impact. The objective was for the panellists to generate individually their reflections before engaging in further interactions. The enquiry form visualised the four transformation stages and was piloted and refined in preparation for the focus-group process (Rowe and Wright, 2011).

With the researchers acting as moderators, each sub-group then moved through the four transformation stages, with panellists naming the key factors and reflecting on their transformation impact. Within the iterative Delphi process, communication is organised by the researchers (Meijering et al., 2013); controlled feedback takes place between iterations, with researchers presenting structured feedback to enable panellists to provide further input (Rowe et al., 1991). The moderators noted and visually displayed the panellists' responses, coded them according to the conceptual framework and clustered them around the four transformation stages to further confirm and discuss them within the sub-groups. At the end of the first round, 
the moderators presented an anonymised and consolidated sub-group report to the wider panel with opportunities for additional feedback.

Following the presentations, the members of the wider panel were asked to share their reflections on the insights gathered from the other sub-groups in the form of a moderated discussion. The comments and reflections of each panel member were again captured by the researchers to be used in the final round.

The third and final round was led by a designated moderator who addressed the large panel. The panel members were first presented with an overview of the previous round, followed by a presentation of the list of factors (consolidated from sub-group lists) allocated to each of the servitization stages. The panel was asked to prioritise these factors based on their relevance and to elaborate on the factors that were deemed most significant in their transformation. Although not all focus group discussions necessarily result in a consensus on prioritisation, views emerge that are supported by different proportions of the group (Parker and Tritter, 2006). The prioritisation and discussion resulted in the identification of the most critical context factors which were used in the analysis.

\subsection{Analysis}

The focus group provided 88 context factors across the servitization stages with associated commentary as data for further analysis. The first step of the analysis focused on the consolidation of the factors to reduce semantic overlap. To minimise bias, the consolidation effort was carried out by two researchers which resulted in a pool of 75 factors. The second step of the analysis focused on the identification and exclusion of very idiosyncratic factors (e.g. 'catastrophic event') as those would not be informative for a generic framework, and this resulted in a pool of 57 factors. In the third step, the individual factors were allocated to the core context dimension for each corresponding transformation stage. The results are presented in the Findings section.

\section{Findings}

This section presents the context factors that the expert panel identified for each servitization stage (i.e. exploration, engagement, expansion and exploitation) with a description of their impacts. Terminologies used by the panellists were adjusted to create coherence and improve 
readability. The individual factors are presented in Figures 2-5, clustered into the themes identified in the literature review ${ }^{4}$.

\subsection{Exploration}

Exploration is the stage where manufacturers seek to find out about the servitization concept (Ziaee Bigdeli and Baines, 2017). The expert panel identified 17 factors that were highlighted for their impact on a manufacturer's servitization progress in the exploration stage; these factors form mostly part of the organisational maturity and capability dimensions (Figure 2).

Several of the identified factors that fall into the organisational maturity dimension (i.e. the sophistication of the manufacturer's management practices) represent power- and politicsrelated themes, highlighting how internal power structures affect the exploration of the servitization concept. The identified factors show how, already at this early stage, support from senior management and key stakeholders is critical to secure the backing and initial resources to engage in a meaningful exploration. Also, the impact of negative customer feedback on progress at the exploration stage was pointed out.

Interestingly, the impact relates to the fact that, manufacturers do not yet have the operational mechanisms required to systematically appraise and learn from feedback, rather than the negativity of the feedback.

The panel also identified leadership-related factors, including the company owner's role in supporting the servitization exploration and the manufacturer's overall experience of revisiting its value proposition. Further, organisational culture-related factors were identified, with the panel highlighting how a shared sales mindset and general willingness to advance the business facilitates the progress in this early servitization stage.

\footnotetext{
${ }^{4}$ The arrow sizes in the figures illustrate the relative emphasis the expert panel put on to that specific dimension at that stage (based on the researchers' interpretation).
} 


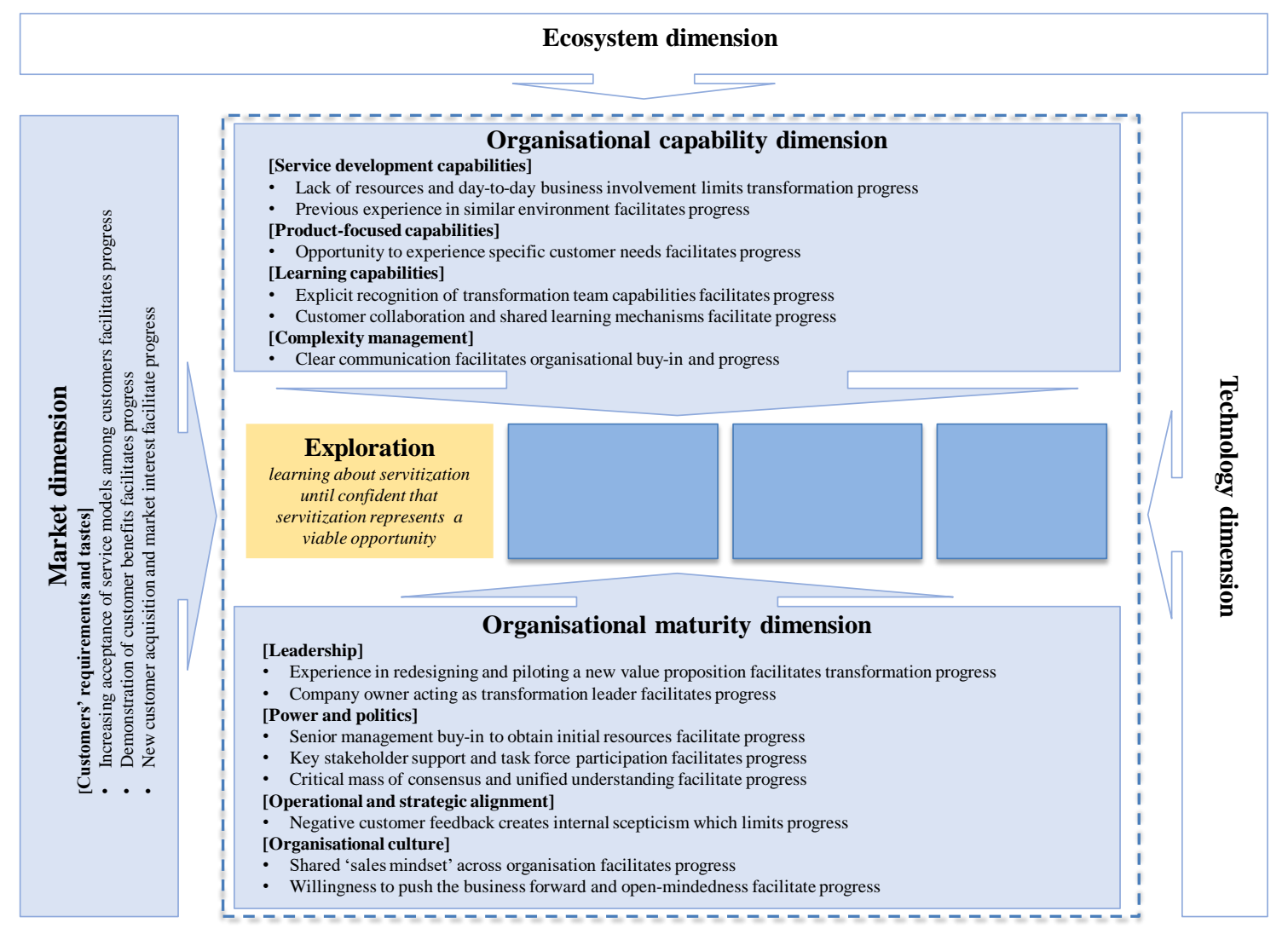

Figure 2. Distribution of factors at the exploration stage

The panellists' reflection on the exploration stage also identified several factors that fall into the organisational capability dimension (i.e. the servitization-specific competences). The identified factors show how the manufacturer's ability to explore the potential of servitization is limited by the lack of service-specific capabilities, as the development of additional capabilities at this stage is restricted owing to the resource demands of day-to-day business. Hence, any previous servitization experience significantly improves the organisation's ability to scope and execute the exploration tasks. Also, extensive product-based customer interactions were identified as improving the servitization exploration as they facilitate a good understanding of customer needs. Further, learning capability-related factors were identified as important to progress in the exploration stage. Panellists pointed to the importance of explicitly recognising the transformation team's capabilities in order to provide confidence and facilitate the required co-exploration of servitization value.

Other factors identified with their impacts in this early exploration stage fall into the market dimension (i.e. the manufacturer's economic environment). The expert panel pointed out how the manufacturer's progress at this stage is supported by the customers' servitization awareness and acceptance. Further, the ability to observe the concrete benefits servitization create for 
customers, as well as the manufacturer's overall drive towards expanding the customer base, facilitate the exploration.

It is important to recognise that none of the identified factors fall into the technology or wider ecosystem dimensions. Hence, the technology push and the larger stakeholder network do not seem to have a recognised impact at this early stage of the manufacturer's transformation.

\subsection{Engagement}

Considerations of the engagement stage (e.g. the systematic evaluation and communication of the servitization business potential) led to the identification of 19 factors covering most of the context dimensions (Figure 3).

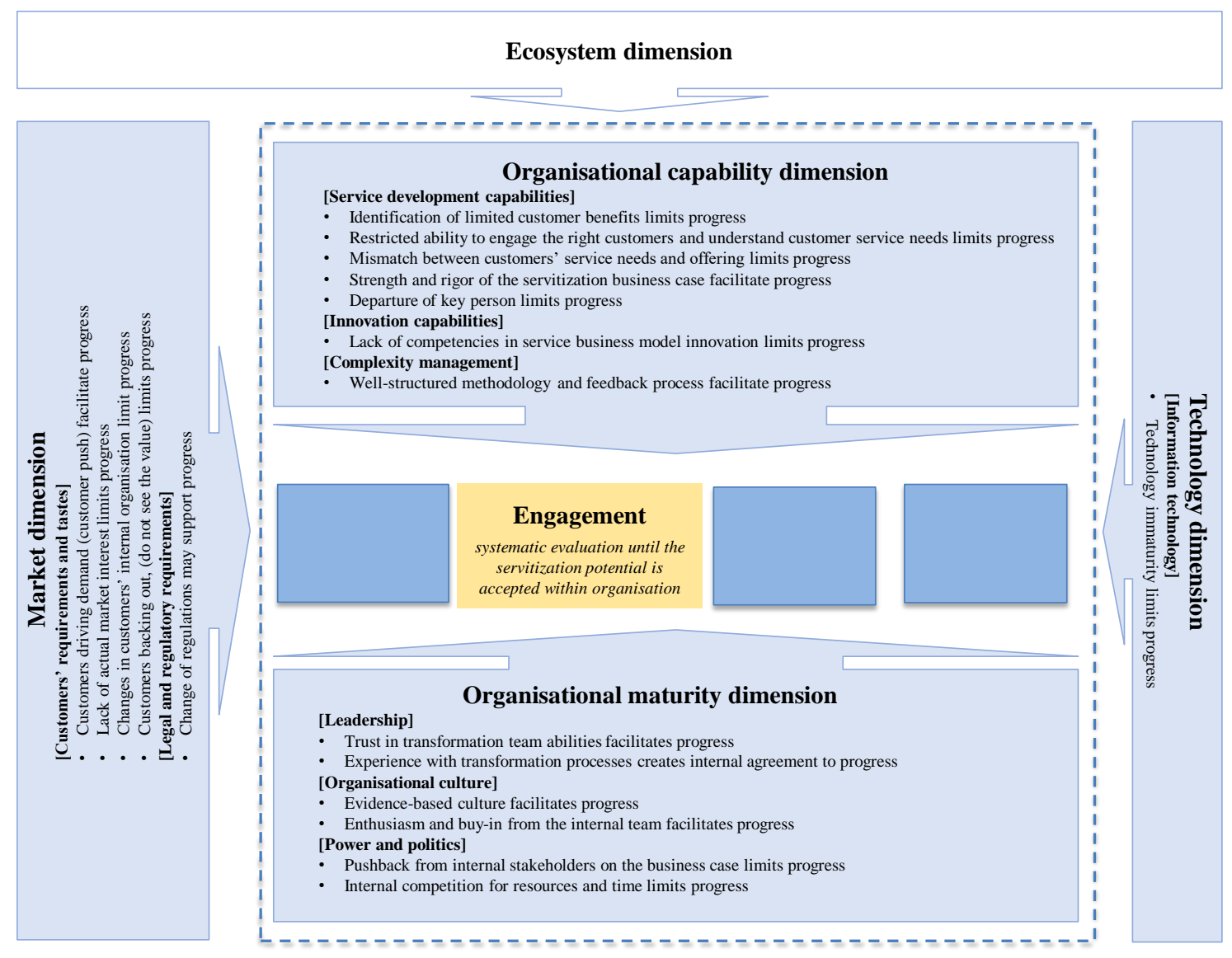

Figure 3. Distribution of factors at the engagement stage

A number of factors identified in the engagement stage fall into the organisational maturity dimension. They cover leadership-related factors, namely the trust in the transformation team and transformation experience, which have been previously identified in the exploration stage. The panel also identified organisational culture-related factors by highlighting how an evidence-based culture and a high level of enthusiasm within the organisation support the 
servitization progress in the engagement stage. Yet, panellists also highlighted how progress at this engagement stage is still vulnerable to the political power of influential stakeholders who might not buy into the servitization business case and the divisiveness of internal resource competition.

Several of the factors identified for the engagement stage also fall into the organisational capability dimension. These involve factors pointing to service development capabilities, with panellists explaining how the manufacturer's inability to understand or integrate customer requirements, or the lack of proficiency to effectively demonstrate customer benefits, hamper progress in the engagement stage. Panellists put an emphasis on the skills needed to advance the transformation at this stage (i.e. the identification of service needs and service business case development) and pointed to difficulties created by the exit of key personnel.

Other factors identified with their impacts in the engagement stage fall into the market dimension (i.e. the manufacturer's economic environment). Specifically, the expert panel highlighted how 'customer push' aids the manufacturer's efforts to obtain wider commitment which is critical in the engagement stage. However, the panellists also mentioned how a lack of market interest in this stage can significantly inhibit servitization progress; a customer's exit from the piloting of the servitized offering or unfavourable changes within a customer's organisation can further impede the process. It was also highlighted how regulatory changes might affect the receptiveness of the market, which facilitates progress at the engagement stage.

The expert panel also identified technology immaturity as a factor impacting servitization progress in the engagement stage (the only technology factor identified in the study). No specific ecosystem-related factors were raised.

\subsection{Expansion}

The expansion stage captures the manufacturer's development of the service offerings and delivery mechanisms to streamline the generation of servitization value (Ziaee Bigdeli and Baines, 2017). The expert panel identified 12 factors with their effects on the servitization progress relevant for this stage (Figure 4). 


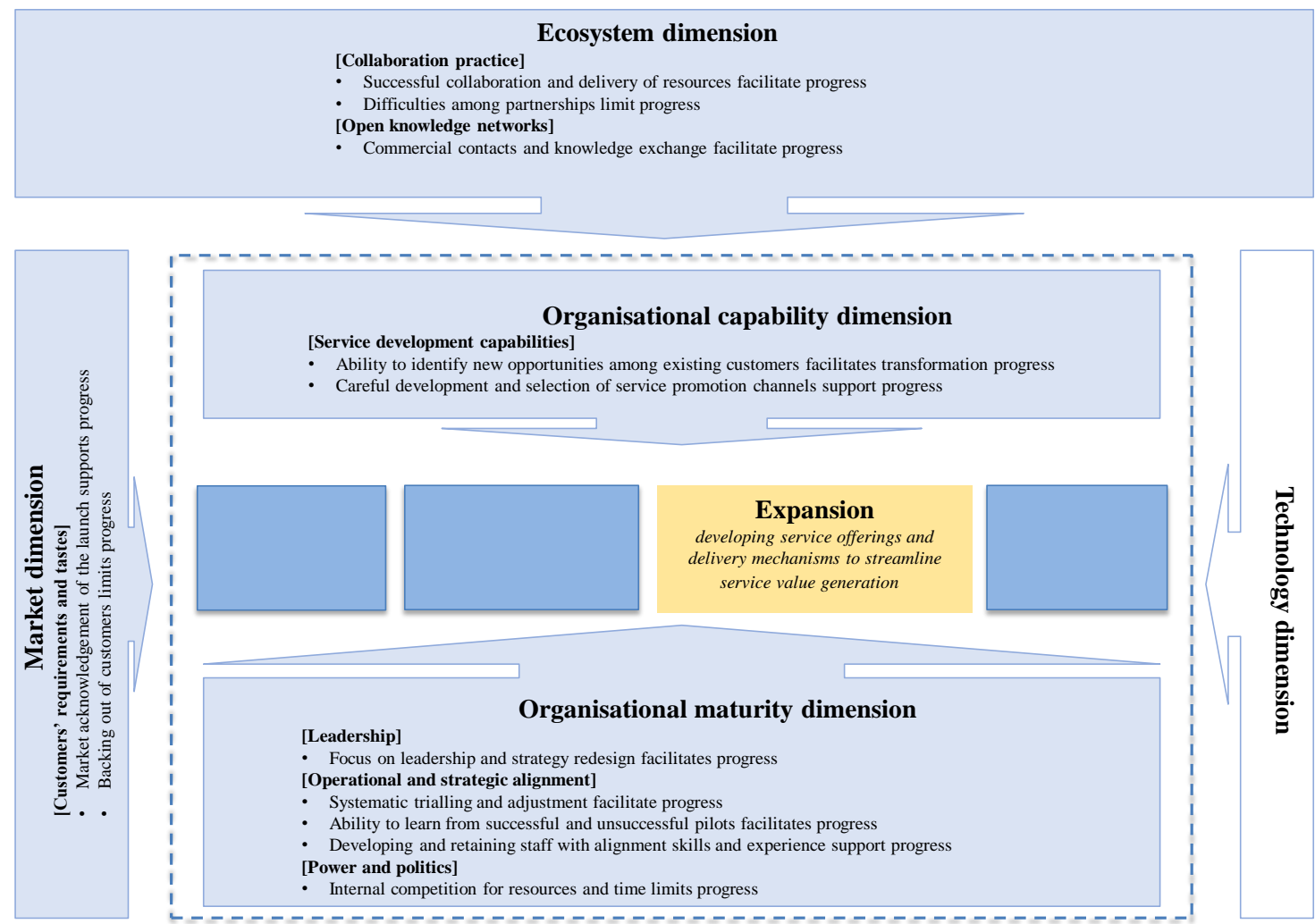

Figure 4. Distribution of factors at the expansion stage

A number of the context factors identified by the panellists for the expansion stage fall into the maturity dimension. It was highlighted that the manufacturer's general strategy revision practices support the transformation as it implies a regular reconsideration of the status quo. The panellists also highlighted the importance of the manufacturer's practice of systematically trialling and adjusting its offerings and the company's willingness to be open and learn from its pilots. Yet, the practice of systematic experimentation is dependent on the manufacturer's ability to retain the staff and leaders that keep the substantial expertise and skills in-house. Panellists further highlighted how advancement at the expansion stage is still vulnerable to the power and politics of internal resource competition (as was the case at the engagement stage).

The panellists' examination of the expansion stage also identified factors that fall into the organisational capability dimension. In particular, it was pointed out that the expansion stage requires the manufacturer to develop specific service marketing competences to establish the required channels to go to market. Also, the ability to develop specific offerings targeted at existing customers to move a product to a service model (without 'cannibalising' the manufacturer's own business) is needed. 
Other identified factors fall into the market dimension. The panel recognised how the market reaction and acknowledgement of the service innovations create further momentum for the expansion stage. However, at the same time, it was highlighted that servitization is still at a very fragile point and the backing out of core customers or the disruption of pilot partnerships can halt progress.

Two ecosystem-related factors were also identified by the panel, highlighting the importance of collaboration across the value chain at this stage and the sharing of resources and knowledge.

\subsection{Exploitation}

Considerations of the exploitation stage (e.g. the continuous optimisation and delivery of the manufacturer's service portfolio) led to the identification of nine factors (Figure 5).

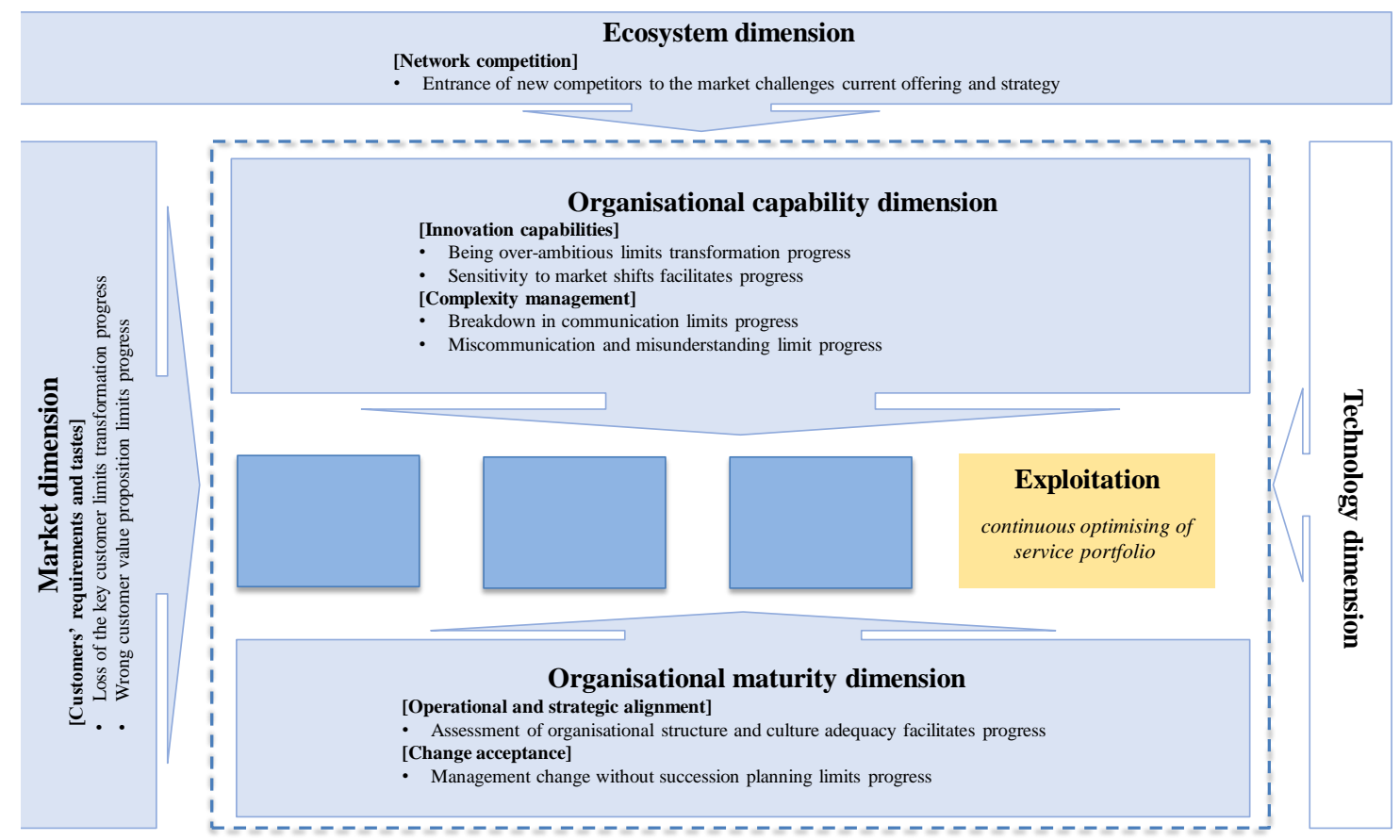

Figure 5. Distribution of factors at the exploitation stage

Several factors identified at the exploitation stage fall into the organisational maturity dimension. They focus on the importance of evaluating and adjusting the organisational structure to accommodate the role of services and maintain an ongoing progress in its continuous exploitation. The panel also pointed to the need for a stable management; hence, the importance of succession planning was identified as a principal factor for the manufacturer's ability to maintain progress at this stage. 
Other factors identified fall into the organisational capability dimension. These highlight the importance of strong delivery efficiency and reliability: the manufacturer needs to focus on providing effective scalable services, and 'being over-ambitious' was said to jeopardise this objective. Interestingly, even at this late stage, the panellists noted that the manufacturer needs to carefully monitor any shifts in service demands so the offering can be continuously adjusted. The importance of communication processes was also pointed out for this exploitation stage, specifically to maintain a close alignment between the manufacturer's product and service business. With regards to the market dimension, it was noted how the manufacturer is impacted (even at this late stage) by the loss of key customers and, in particular, how the customer value proposition previously developed continues to impact the manufacturer. The panel also identified an ecosystem-related factor by debating how the entrance of new players into the market (i.e. digital service providers) could threaten the newly adopted and scaled servitized business model.

\section{Discussion}

This study sets out to develop a holistic understanding of the manufacturer's servitization process and the contextual factors that impact such a transformation. It adds to previous studies that recognise that different internal and external context factors have an impact on the manufacturer's transformation (Turunen and Finne, 2014, Baines et al., 2017). The findings not only add to the range of factors but also delineate these factors and demonstrate how they impact servitization at different transformation stages. Interestingly, the findings show that both internal dimensions (i.e. capability and maturity factors) are identified as critical throughout all transformation stages, while the external dimensions (i.e. technology, market and ecosystem factors) are mostly identified as critical in the intermediary engagement and expansion stages. So, it seems that the manufacturer's servitization progress in the intermediary stages (with a service evaluation and development focus) is a lot more exposed to external context factors than in the initial and final stages (with a learning and optimisation focus).

Although, at this point, it is not clear to what extent these findings are limited to small- and medium-sized manufacturers, they help to broaden the understanding of the range of factors that, in practice, may direct a manufacturer's transformation. More specifically, they provide an opportunity to theorise about particular implications that customer-, trust- and operationalexcellence-related factors create across the different servitization stages. 


\subsection{Customers across stages}

The importance of customers in a servitization context playing an active role (i.e. value cocreation), instead of remaining passive consumers, has already been recognised in the wider servitization literature (Prahalad and Ramaswamy, 2000, Neely, 2008). Understanding how customers have an impact on a manufacturer's servitization journey across its different stages emerges as one of the central findings of this study.

Even at the exploration stage, the findings show that customer comments indicating receptiveness to servitization ideas create an important early impetus to the manufacturer's transformation efforts, especially when the push is coming from existing customers. Hence, these early discussions with customers not only aid in demonstrating the potential servitization opportunities but also help to advance the manufacturer's learning process and transformation.

However, not all customers are willing to accept the shift towards service-based offerings (Kowalkowski, 2011, Storbacka et al., 2013) and the manufacturer might also receive negative feedback as part of these initial interactions. The findings show that such negative feedback at this early stage can significantly limit the manufacturer's transformation progress by giving rise to internal scepticism. The manufacturer, at this stage, seems particularly vulnerable to negative comments as it is not yet set up to systematically gather and evaluate customer feedback to put these comments into context and adjust its strategies. These findings create implications for the way initial customer interactions should be managed and communicated within the wider organisation.

The findings of the engagement stage specifically point to the lack of organisational capability to absorb customer feedback as an aspect that limits the transformation progress (e.g. 'restricted ability to engage the right customers', 'identification of limited customer benefit', 'mismatch between customers' service needs and offering'). It seems that, at this stage, which focuses on the systematic evaluation of the servitization opportunities, the development of the manufacturer's internal capability to systematically learn from customer interactions is critical. While it could be argued that this limited internal capability is specific to the case of small- and medium-sized manufacturers and their constrained resources (Gebauer et al., 2012b, Ceci and Masini, 2011), similar concerns have been expressed for large multinationals whose servitization progress has reportedly been sensitive to their ability to learn from customers (Valtakoski, 2017, Parida et al., 2014). Developing customer-interface capabilities as early as possible in the servitization process allows the manufacturer to overcome cultural and 
organisational resistance both within the organisation and in external partnerships (Alghisi and Saccani, 2015). However, it is alarming that, in this critical learning stage, which forms the basis for determining servitization potential, the manufacturer seems highly dependent on individual customers and are, therefore, exposed to any customer disengagements.

While the engagement stage is dominated by concerns over the manufacturer's internal capacity to effectively utilise customer feedback, the customer-related findings in the expansion stage highlight the customers from an external context perspective. At the expansion stage, the customers' reluctance to co-operate compromises transformation efficiency, especially when the piloting of servitized offerings does not lead to long-term contracts. The literature shows that the customers' reluctance to engage in value co-creation efforts affects the servitizing manufacturers, that are expected to co-develop with their partners (Martinez et al., 2017, Story et al., 2017). The findings also highlight that, at this point, the manufacturer becomes further exposed to customers' individual and possibly divergent service requirements, which makes it more difficult to streamline the generation of servitization value and advance the transformation.

The findings further show that, in the exploitation stage, the manufacturer's transformation continues to be impacted by its customers. As the manufacturer progresses with its transformation, the level of external cooperation and interaction with other actors in the ecosystem becomes more intense (Windahl and Lakemond, 2006, Roehrich and Lewis, 2010). This intense cooperation, as well as the fact that the manufacturer seems to build its servitization efforts around its key customers, becomes a critical risk factor for its transformation efforts. Hence, even at this late stage, the panellists cited the 'loss of key customers' as a factor limiting the manufacturer's transformation process.

With the heavy reliance of servitization on value-co-creation (Jaakkola and Hakanen, 2013), the manufacturer's dependency on its customers far exceeds the dependency of traditional product sales-based models. While a strong relationship with customers and a fuller understanding of customers' needs have already been confirmed as robust servitization enablers (Raja et al., 2013), the findings of this research show the diverse nature of these dependencies and their relative importance at the different stages of the manufacturer's servitization. 


\subsection{Trust across stages}

The findings also highlight the importance that trust plays in the course of the manufacturer's transformation. The wider literature highlights that servitization brings about considerable uncertainty over the manufacturer's service competencies (Sousa and da Silveira, 2017, Kreye, 2017), partnerships (Durugbo and Riedel, 2013) or delivery mechanisms (Durugbo and Erkoyuncu, 2016). Several factors identified across the maturity and capability dimensions, as well as the market and ecosystem dimensions, contribute to the manufacturer's ability to create trust in order to manage this uncertainty.

Even at the early stage of exploration, the findings identify the importance of the manufacturer explicitly recognising the servitization team's capability and clearly communicating servitization ideas to create organisational buy-in. Trust creation further emerges at the engagement stage, where the importance of highlighting the transformation team's abilities is again recognised.

As the manufacturer moves from a learning to a development focus (i.e. engagement to expansion), it is of interest to observe how trust-related concerns shift from a competency to an objectivity focus. At the expansion stage, balancing service and product business becomes critical and the manufacturer's ability to objectively (and fairly) consolidate these competing objectives becomes an important trust issue for employees working on the different sides of the business.

Another trust-related issue that emerges at the expansion stage refers to the piloting of the value proposition and the culture of 'learning from failure'. By highlighting the importance of 'learning from successful and unsuccessful pilots', the panellists emphasised how the expansion stage requires a trust-based culture of experimentation to enable learning from successful as well as unsuccessful pilots without reprimand. This finding aligns with the arguments from the wider servitization literature on how setting the correct organisational culture with appropriate employee motivation mechanisms is important for implementing servitization strategies (Kreye, 2016).

Notably, , the findings also expand the notion of trust in servitization from an external to an internal context perspective. Servitization research has largely considered 'trust' when focusing on inter-organisational collaboration (Reim et al., 2015, Kindström, 2010, Bastl et al., 2012), while our findings point to an internal notion of trust (i.e. trust in own competencies). 


\subsection{Operational excellence across stages}

The findings also point to the importance of operational excellence across the stages of transformation. At the exploration stage, aspects of operational excellence emerge in comments highlighting the value of systematic methods for successful learning about servitization. The ability to learn is critical for the development of streamlined service delivery, structures and practices within the organisation (Brax and Jonsson, 2009). However, comments from the panellists suggest that the manufacturer explores servitization in an ad-hoc manner, which limits important learning opportunities.

Comments made about the engagement stage describe how critical the use of established methodologies and an evidence-based culture are for the manufacturer's ability to achieve its evaluation objectives. Although the role of utilising systematic evaluation methods in servitization has already been recognised (Ziaee Bigdeli et al., 2018), the lack of experience in conducting these evaluations (which may be a particular challenge for small- and mediumsized manufacturers that might seek to integrate into larger company's value streams to servitize (Clegg et al., 2017), therefore exposing themselves to uncertainty) may still threaten the manufacturer's transformation progress.

The findings further show how the expansion stage is also impacted by operational excellencerelated factors, with comments focusing on organisational and operational adjustments to deliver servitized offerings. Regular attention to staff, in terms of systematic human resource development and retention and succession planning, addresses aspects of operational excellence, which, although not specific to servitization, seem to be important for the manufacturer's successful transformation.

Comments about structured communication, feedback and evaluation practices also dominated discussions of the exploitation stage, further highlighting the importance of operational excellence in achieving an efficient service delivery. The prioritisation of operational excellence puts into perspective the fact that servitization represents a significant operational change which benefits from a focus and practice of operational excellence. However, it also shows that, as the challenges differ across the stages, so do the aspects of operational excellence that facilitate progress in these stages. 


\subsection{The absence of factors}

Moreover, of interest in the findings is the absence of some of the context factors the literature review had previously identified as critical for servitization. Technology, in particular, is frequently highlighted in the literature as a fundamental enabler or driver of servitization (Coreynen et al., 2017, Story et al., 2017, Parry et al., 2016, Baines and Lightfoot, 2014, Lightfoot et al., 2011, Hsu, 2007). Yet, surprisingly, only one of the factors identified in the present study refers to a technology-related concern ('technology immaturity limits progress'). It seems that the panel members perceive technology as neither a major stumbling block nor an accelerator of the manufacturer's transformation; an observation that challenges the technology focus of the servitization literature.

Two possible explanations may reconcile the mismatch between the emphasis that servitization literature puts on technology and the lack of emphasis expressed by the panel. First, for the panel, specific technology concerns may have been overshadowed by more pressing strategic and organisational factors that impact the manufacturer's servitization effort. Second, smalland medium-sized manufacturers are likely to draw on externally developed information technologies and their developments may therefore be only of indirect concern.

The relative absence of 'leadership' as an explicit factor throughout the different stages is of interest. The extant literature emphasises the importance of the wider leadership role to build a new service culture (Kowalkowski et al., 2017, Gebauer and Friedli, 2005), direct the interaction between product and service business (Peillon et al., 2015) and manage the tensions of a possible cannibalisation between product and service business (Kindström et al., 2014). Yet, in this study, reference to leadership as an important context factor is largely limited to exploration-stage considerations, which highlight the importance of 'senior management buyin', 'key stakeholder buy-in' and the role of the 'company owner as transformation leader'. Based on these observations, it could be argued that servitization may not only require visible top-down leadership commitment in the early stages of transformation, but (given the range of tensions that emerge as the idea progresses) a broader basis of bottom-up commitment to turn the ideas into actions and operations.

\section{Conclusions}

\subsection{Contributions to servitization research}

The study and its findings provide a number of specific contributions to servitization research and theory development. First, the findings provide a helpful empirical angle to the, otherwise 
conceptual, servitization stage models (Kowalkowski and Ulaga, 2017, Martinez et al., 2017, Ziaee Bigdeli and Baines, 2017). Drawing on the cases of small- and medium-sized manufacturers, a fine-grained understanding is created that identifies those context factors that impact the manufacturer's transformation across different stages. Further, the study theoretically grounds the notion of servitization stage models by integrating metamorphic transformation theory (Meyer et al., 1990) and the organisational change literature (Pettigrew, 2012) to draw out the core dimensions of a multi-stage perspective on servitization.

Second, the study also contributes to the development of a detailed understanding of the transformation context that impacts the manufacturer's servitization progress. While the impact individual context factors have on the manufacturer's servitization progress is already being explored (see Tables 1-5), there is a growing interest in considering a wider range of context factors cumulatively to appropriately reflect the associated organisational complexity (Turunen and Finne, 2014, Finne et al., 2013, Gebauer, 2008). The present study formalises the range of internal and external dimensions that characterise the manufacturer's servitization context and illustrates the diversity of critical context factors with the nature of their implications.

Third, the study further contributes to servitization theory development by bringing attention to the link between contextual forces and the manufacturer's stage of transformation which has brought into focus the integration of the two underlying theoretical perspectives (multi-stage transformation and multi-dimensional organisational context). The study draws on the experiences of small- and medium-sized manufacturers to empirically advance this integrated perspective and is hereby addressing calls to specifically investigate this segment of servitizing manufacturers (Mennens et al., 2018, Kowalkowski et al., 2013, Gebauer et al., 2012b).

\subsection{Contributions to servitization practice}

The study also provides a number of implications for business practice. By drawing on the collective experience and expectations of 25 senior executives, representing 17 small- and medium-sized manufacturers actively involved in servitization, a comprehensive roadmap has been created that illustrates the concrete challenges the manufacturer may be facing in the course of its servitization.

The study also identifies the manufacturer's high dependence on individual customers as a clear threat to its transformation across all stages. Hence, to minimise the impact of an individual customer's abandonment of the joint servitization effort, the manufacturer is advised 
to engage with a wide range of customers. Critically, the importance of engaging with a wide range of customers is not limited to the later expansion or exploitation stages but also applies to the early exploration and engagement stages which focus on learning about servitization and evaluating its business potential. The role of customers in the manufacturer's learning and evaluation is instrumental. Customer abandonment threatens the build-up of the manufacturer's critical internal momentum and risks the manufacturer developing its servitization understanding and service offerings in isolation, detached from the needs of the market. The manufacturer that builds service business cases with significant customer input strengthens its chances of success in the later stages (Gebauer et al., 2012b, Leseure et al., 2010).

\subsection{Limitations}

Despite the range of the study's contributions, it is also important to note its limitations. First, a review of the literature was conducted to illustrate the dimensions of Ziaee Bigdeli and Baines's (2017) proposed framework and establish its underlying themes. Although considerable care was taken to capture a wide range of themes, the article prioritisation and theme development were based on the research team's shared effort; it cannot be excluded that other teams would select other articles or develop other themes to illustrate the framework.

Second, the method that was selected to identify and prioritise the panel members' context factors is sensitive to participants' interactions. These dynamic interactions provide important opportunities to elicit diverse perspectives, although the emerging data and themes are openended and may be subject to conceptual overlaps (Gibbs, 1997). By ensuring that each panel sub-group was carefully guided by at least one researcher to moderate the entire focus-group process, register responses and provide intermediate feedback, these limitations were kept to a minimum as far as possible.

Third, the panel member selection might have also affected the results. While the clear attribution of the manufacturer's servitization progress into a transformation stage is difficult (it may be involved in activities that fall into different stages), a diversity of stages was represented. Hence, for some members, the discussion of the context factors drew on past experiences, and also on future anticipations based on their industry and organisational experience. Future forecasting is permissible in consensus-based group techniques (Hsu and Sandford, 2007) and the inclusion of manufacturing representatives from more advanced transformation stages helped to address this limitation. Further, with the study broadly drawing 
on Pettigrew's $(1985,1987)$ organisational transformation notion, it does not consider the role of the individual decision- maker in detail. The impact exploration in this study has been limited to eliciting its meaning (Bloor, 2001) and identifying the priorities for future research and deliberations based on the established areas of consensus (Harvey and Holmes, 2012). To develop a more fine-grained understanding of the context-factor's impact, it would be of interest to focus explicitly on the role of the decision-maker and explore the divergences in the decision-maker's interpretations.

Fourth, drawing data from small- and medium-sized manufacturers might have limited the extent to which the study's findings can be applied to a broader range of manufacturers (multinationals in particular). However, as a number of findings resonate with the wider servitization literature (which generally focuses on large manufacturers), it can be expected that the framework and a number of the specific insights created can contribute to servitization research in general.

\subsection{Opportunities for future research}

The study and its findings suggest several opportunities for future research. The study adapted Ziaee Bigdeli and Baines's (2017) model which assumes manufacturers to progress sequentially through four transformation stages. Such an assumption is reasonable for small manufacturers, which are unlikely to engage in several parallel transformations.

However, for larger manufacturers with diverse product lines, servitization efforts are likely to take place alongside each other (Raddats et al., 2015, Visnjic Kastalli and Van Looy, 2013). Hence, these parallel transformations may become additional context dimensions for each other. Following March (1991), an organisation's ability to exploit a product or service provision provides the foundation for exploring another product or service opportunity, making them inextricably linked (Yalcinkaya et al., 2007). Investigating how the manufacturer balances these exploration and exploitation efforts, and their cross-fertilisation to reduce rampup time for new service propositions (Menor et al., 2002), represents important future research opportunities that extend the present findings to the transformations of large manufacturers.

Further, future research could build on the range of contextual factors that the present study has identified, quantify the impact these factors create and verify their causal dependencies. It would be of practical use to determine the factors that are the easiest to address, also, to determine those which are the most important to tackle. Transformation research in related 
areas have already engaged in such considerations (Hannan and Freeman, 1977, Aldrich and Pfeffer, 1976, Child, 1972, Goodstein, 1994) and comparable additional servitization-focused investigations would help to determine the extent of the manufacturer's strategic choice and to explain how the manufacturer responds differently to contextual pressures. In addition, future research could also focus on the individual decision-maker's sense-making process to explain the diversity of adaptations that were observed in the present research (e.g. see Siltaloppi (2015)).

The model developed in the research also provides an opportunity to advance the understanding of how the manufacturer can modify its context through its servitization efforts (Hitt and Tyler, 1991, Child, 1972). The present study only considers what implications the context has for servitization, without exploring the reverse scenario, that servitization impacts on the manufacturer's context. Yet, evidence from related domains suggest that such reverse impact scenarios can take place (Hitt et al., 2007).

The study has conceptualised servitization as a long-term transformation process that requires the manufacturer to consider carefully its internal and external context to manage this effort effectively. For servitization research, it is critical to move ahead and assist the manufacturer in understanding, anticipating and managing this transformation and the complexity the process involves. The present explorative study offers the conceptual and empirical basis for the development of such a transformation guidance. 


\section{References}

AHAMED, Z., INOHARA, T. \& KAMOSHIDA, A. 2013. The Servitization of manufacturing: An empirical case study of IBM Corporation. International Journal of Business Administration, 4, p18.

ALDRICH, H. E. \& PFEFFER, J. 1976. Environments of organizations. Annual Review of Sociology, 2, 79-105.

ALGHISI, A. \& SACCANI, N. 2015. Internal and external alignment in the servitization journey - Overcoming the challenges. Production Planning \& Control, 26, 1219-1232.

AMBROISE, L. 2018. The environment-strategy-structure fit and performance of industrial servitized SMEs. Journal of Service Management, 29, 301-328.

ATES, A. \& BITITCI, U. 2011. Change process: a key enabler for building resilient SMEs. International Journal of Production Research, 49, 5601-5618.

BAINES, T., ZIAEE BIGDELI, A., BUSTINZA, O. F., SHI, V. G., BALDWIN, J. \& RIDGWAY, K. 2017. Servitization: Revisiting the state-of-the-art and research priorities. International Journal of Operations \& Production Management, 37, 256278.

BAINES, T., ZIAEE BIGDELI, A, SOUSA, R. \& SCHROEDER, A., 2019. Framing the servitization transformation process: A model to understand and facilitate the servitization journey. International Journal of Production Economics. (in press)

BAINES, T., LIGHTFOOT, H., BENEDETTINI, O. \& KAY, J. M. 2009a. The servitization of manufacturing: A review of literature and reflection on future challenges. Journal of Manufacturing Technology Management, 20, 547-567.

BAINES, T., LIGHTFOOT, H., PEPPARD, J., JOHNSON, M., TIWARI, A., SHEHAB, E. \& SWINK, M. 2009b. Towards an operations strategy for product-centric servitization. International Journal of Operations \& Production Management, 29, 494-519.

BAINES, T. \& LIGHTFOOT, H. W. 2014. Servitization of the manufacturing firm: Exploring the operations practices and technologies that deliver advanced services. International Journal of Operations \& Production Management, 34, 2-35.

BAINES, T. \& SHI, V. G. 2015. A Delphi study to explore the adoption of servitization in UK companies. Production Planning \& Control, 1-17.

BAKER, J., LOVELL, K. \& HARRIS, N. 2006. How expert are the experts? An exploration of the concept of 'expert'within Delphi panel techniques. Nurse Researcher, 14, 59-70.

BARDECKI, M. J. 1984. Participants' response to the Delphi method: An attitudinal perspective. Technological Forecasting and Social Change, 25, 281-292.

BARNES, D. 2002. The complexities of the manufacturing strategy formation process in practice. International Journal of Operations \& Production Management, 22, 10901111.

BASTL, M., JOHNSON, M., LIGHTFOOT, H. \& EVANS, S. 2012. Buyer-supplier relationships in a servitized environment: An examination with Cannon and Perreault's framework. International Journal of Operations \& Production Management, 32, 650675.

BENEDETTINI, O., NEELY, A. \& SWINK, M. 2015. Why do servitized firms fail? A riskbased explanation. International Journal of Operations \& Production Management, 35, 946-979.

BLOOR, M. 2001. Focus groups in social research, Sage.

BRADY, S. R. 2015. Utilizing and adapting the Delphi method for use in qualitative research. International Journal of Qualitative Methods, 14, 1609406915621381. 
BOKRANTZ, J., SKOOGH, A., BERLIN, C. \& STAHRE, J. 2017. Maintenance in digitalised manufacturing: Delphi-based scenarios for 2030. International Journal of Production Economics, 191, 154-169.

BRAX, S. A. \& JONSSON, K. 2009. Developing integrated solution offerings for remote diagnostics: A comparative case study of two manufacturers. International Journal of Operations \& Production Management, 29, 539-560.

BRAX, S. A. \& VISINTIN, F. 2015. Meta-model of servitization: The integrative profiling approach. Industrial Marketing Management, 60, 17-32.

BURTON, J., STORY, V. M., RADDATS, C. \& ZOLKIEWSKI, J. 2017. Overcoming the challenges that hinder new service development by manufacturers with diverse services strategies. International Journal of Production Economics, 1-11.

BUSTINZA, O., VENDRELL HERRERO, F., GOMES, E., LAFUENTE GONZÁLEZ, E. M., OPAZO-BASÁEZ, M., RABETINO, R. \& VAILLANT, Y. 2018. Product-service innovation and performance: Unveiling the complexities. International Journal of Business Environment, 10, 95-111.

BUSTINZA, O. F., BIGDELI, A. Z., BAINES, T. \& ELLIOT, C. 2015. Servitization and competitive advantage: the importance of organizational structure and value chain position. Research-Technology Management, 58, 53-60.

BUSTINZA, O. F., PARRY, G. C. \& VENDRELL-HERRERO, F. 2013. Supply and demand chain management: The effect of adding services to product offerings. Supply Chain Management - An International Journal, 18, 618-629.

CECI, F. \& MASINI, A. 2011. Balancing specialized and generic capabilities in the provision of integrated solutions. Industrial and Corporate Change, 20, 91-131.

CENAMOR, J., RÖNNBERG SJÖDIN, D. \& PARIDA, V. 2017. Adopting a platform approach in servitization: Leveraging the value of digitalization. International Journal of Production Economics, 192, 54-65.

CHESBROUGH, H. W. 2011. Bringing open innovation to services. MIT Sloan Management Review, 52, 85.

CHILD, J. 1972. Organizational structure, environment and performance: The role of strategic choice. Sociology, 6, 1-22.

CLEGG, B., LITTLE, P., GOVETTE, S. \& LOGUE, J. 2017. Transformation of a small-tomedium-sized enterprise to a multi-organisation product-service solution provider. International Journal of Production Economics, 0-1.

COREYNEN, W., MATTHYSSENS, P. \& VAN BOCKHAVEN, W. 2017. Boosting servitization through digitization: Pathways and dynamic resource configurations for manufacturers. Industrial Marketing Management, 60, $42-53$.

CRITCHER, C. \& GLADSTONE, B. 1998. Utilizing the Delphi technique in policy discussion: A case study of a privatized utility in Britain. Public Administration, 76, 431-449.

DAFT, R. L., SORMUNEN, J. \& PARKS, D. 1988. Chief executive scanning, environmental characteristics, and company performance: An empirical study. Strategic Management Journal, 9, 123-139.

DALKEY, N. \& HELMER, O. 1963. An experimental application of the Delphi method to the use of experts. Management Science, 9, 458-467.

DURUGBO, C. \& ERKOYUNCU, J. A. 2016. Mitigating uncertainty for industrial service operations: A multi case study. International Journal of Operations \& Production Management, 36, 532-571.

DURUGBO, C. \& RIEDEL, J. C. 2013. Readiness assessment of collaborative networked organisations for integrated product and service delivery. International Journal of Production Research, 51, 598-613. 
ELORANTA, V. \& TURUNEN, T. 2016. Platforms in service-driven manufacturing: Leveraging complexity by connecting, sharing, and integrating. Industrial Marketing Management, 55, 178-186.

EUROPEAN COMMISSION 2018. Study on the potential of servitisation and other forms of product-service provision for EU SMEs. Retrieved 26/8/2019 from https://publications.europa.eu/en/publication-detail/-/publication/0d1ed8aa-864911e8-ac6a-01aa75ed71a1/language-en

FAEMS, D., VAN LOOY, B., JANSSENS, M. \& VLAAR, P. W. 2012. The process of value realization in asymmetric new venture development alliances: Governing the transition from exploration to exploitation. Journal of Engineering and Technology Management, 29, 508-527.

FINNE, M., BRAX, S. \& HOLMSTRÖM, J. 2013. Reversed servitization paths: A case analysis of two manufacturers. Service Business, 7, 513-537.

FORKMANN, S., HENNEBERG, S. C., WITELL, L. \& KINDSTRÖM, D. 2017. Driver configurations for successful service infusion. Journal of Service Research, 20, 275291.

FRISHAMMAR, J. 2006. Organizational environment revisited: A conceptual review and integration. International Studies of Management \& Organization, 36, 22-49.

GAGO, D. \& RUBALCABA, L. 2007. Innovation and ICT in service firms: Towards a multidimensional approach for impact assessment. Journal of Evolutionary Economics, $17,25-44$.

GEBAUER, H. 2008. Identifying service strategies in product manufacturing companies by exploring environment-strategy configurations. Industrial Marketing Management, 37, 278-291.

GEBAUER, H., BRASHEAR, T. \& KOWALKOWSKI, C. 2012a. Customer-focused and service-focused orientation in organizational structures. Journal of Business \& Industrial Marketing, 27, 527-537.

GEBAUER, H., FLEISCH, E. \& FRIEDLI, T. 2005. Overcoming the service paradox in manufacturing companies. European Management Journal, 23, 14-26.

GEBAUER, H. \& FRIEDLI, T. 2005. Behavioral implications of the transition process from products to services. Journal of Business \& Industrial Marketing, 20, 70-78.

GEBAUER, H., FRIEDLI, T. \& FLEISCH, E. 2006. Success factors for achieving high service revenues in manufacturing companies. Benchmarking: An International Journal, 13, 374-386.

GEBAUER, H., PAIOLA, M. \& EDVARDSSON, B. 2012b. A capability perspective on service business development in small and medium-sized suppliers. Scandinavian Journal of Management, 28, 321-339.

GIBBS, A. 1997. Focus groups. Social Research Update, 19, 1-8.

GOODSTEIN, J. D. 1994. Institutional pressures and strategic responsiveness: Employer involvement in work-family issues. Academy of Management Journal, 37, 350-382.

HANNAN, M. T. \& FREEMAN, J. 1977. The population ecology of organizations. American Journal of Sociology, 82, 929-964.

HARVEY, N. \& HOLMES, C. A. 2012. Nominal group technique: An effective method for obtaining group consensus. International Journal of Nursing Practice, 18, 188-194.

HASSON, F., KEENEY, S. \& MCKENNA, H. 2000. Research guidelines for the Delphi survey technique. Journal of Advanced Nursing, 32, 1008-1015.

HE, Z. L. \& WONG, P. K. 2004. Exploration vs. exploitation: An empirical test of the ambidexterity hypothesis. Organization Science, 15, 481-494.

HELFAT, C. E. \& LIEBERMAN, M. B. 2002. The birth of capabilities: Market entry and the importance of pre-history. Industrial and Corporate Change, 11, 725-760. 
HITT, M. A., BEAMISH, P. W., JACKSON, S. E. \& MATHIEU, J. E. 2007. Building theoretical and empirical bridges across levels: Multilevel research in management. Academy of Management Journal, 50, 1385-1399.

HITT, M. A. \& TYLER, B. B. 1991. Strategic decision models: Integrating different perspectives. Strategic Management Journal, 12, 327-351.

HOLMSTRÖM, J. \& PARTANEN, J. 2014. Digital manufacturing-driven transformations of service supply chains for complex products. Supply Chain Management: An International Journal, 19, 421-430.

HSU, C. C. \& SANDFORD, B. A. 2007. The Delphi technique: Making sense of consensus. Practical Assessment, Research \& Evaluation, 12, 1-8.

HSU, C. Scaling with digital connection: Services innovation. Systems, Man and Cybernetics, 2007. ISIC. IEEE International Conference on, 2007. IEEE, 4057-4061.

HUDSON, M., LEAN, J. \& SMART, P. A. 2001. Improving control through effective performance measurement in SMEs. Production planning \& control, 12, 804-813.

JAAKKOLA, E. \& HAKANEN, T. 2013. Value co-creation in solution networks. Industrial Marketing Management, 42, 47-58.

JOHNSON, M. \& MENA, C. 2008. Supply chain management for servitised products: A multiindustry case study. International Journal of Production Economics, 114, 27-39.

JOHNSTONE, S., DAINTY, A. \& WILKINSON, A. 2009. Integrating products and services through life: An aerospace experience. International Journal of Operations \& Production Management, 29, 520-538.

JOVANOVIC, M., ENGWALL, M. \& JERBRANT, A. 2016. Matching service offerings and product operations: A key to servitization success. Research Technology Management, 59, 29-36.

KAMP, B. \& PARRY, G. 2017. Servitization and advanced business services as levers for competitiveness. Industrial Marketing Management, 60, 11-16.

KINDSTRÖM, D. 2010. Towards a service-based business model - Key aspects for future competitive advantage. European Management Journal, 28, 479-490.

KINDSTRÖM, D., DANIEL KINDSTRÖM, D. C. K. D. \& KOWALKOWSKI, C. 2014. Service innovation in product-centric firms: A multidimensional business model perspective. Journal of Business \& Industrial Marketing, 29, 96-111.

KINDSTRÖM, D. \& KOWALKOWSKI, C. 2015. Service-driven business model innovation: Organizing the shift from a product-based to a service-centric business model. Business Model Innovation: The Organizational Dimension. Nicolai Foss and Tina Saebi (Eds.), Oxford University Press, UK, 191-216.

KOHTAMÄKI, M., PARTANEN, J. \& MÖLLER, K. 2013a. Making a profit with R\&D services-The critical role of relational capital. Industrial Marketing Management, 42, 71-81.

KOHTAMÄKI, M., PARTANEN, J., PARIDA, V. \& WINCENT, J. 2013b. Non-linear relationship between industrial service offering and sales growth: The moderating role of network capabilities. Industrial Marketing Management, 42, 1374-1385.

KOWALKOWSKI, C. 2011. Dynamics of value propositions: Insights from service-dominant logic. European Journal of Marketing, 45, 277-294.

KOWALKOWSKI, C., GEBAUER, H., KAMP, B. \& PARRY, G. 2017. Servitization and deservitization: Overview, concepts, and definitions. Industrial Marketing Management, 60, 4-10.

KOWALKOWSKI, C., GEBAUER, H. \& OLIVA, R. 2017. Service growth in product firms: Past, present, and future. Industrial Marketing Management, 60, 82-88.

KOWALKOWSKI, C. \& ULAGA, W. 2017. Service strategy in action: A practical guide for growing your B2B service and solution business. Service Strategy Press. 
KOWALKOWSKI, C., WITELL, L. \& GUSTAFSSON, A. 2013. Any way goes: Identifying value constellations for service infusion in SMEs. Industrial Marketing Management, 42, 18-30.

KREYE, M. E. 2016. Employee motivation in product-service system providers Production Planning \& Control, 27, 1249-1259.

KREYE, M. E. 2017. Can you put too much on your plate? Uncertainty exposure in servitized triads. International Journal of Operations \& Production Management, 37, 1722-1740.

LEE, J., KAO, H. A. \& YANG, S. 2014. Service innovation and smart analytics for Industry 4.0 and Big Data environment. Procedia CIRP, 16, 3-8.

LESEURE, M., HUDSON-SMITH, M., MARTINEZ, V., BASTL, M., KINGSTON, J. \& EVANS, S. 2010. Challenges in transforming manufacturing organisations into product-service providers. Journal of Manufacturing Technology Management.

LIENERT, A. Change of culture or culture of change? Introducing a path-agency-culture (PAC) framework to servitization research. Procedia CIRP, 2015. Elsevier, 353-358.

LIGHTFOOT, H. W., BAINES, T. \& SMART, P. 2011. Examining the information and communication technologies enabling servitized manufacture. Proceedings of the Institution of Mechanical Engineers, Part B: Journal of Engineering Manufacture, 225, 1964-1968.

LÜTJEN, H., TIETZE, F. \& SCHULTZ, C. 2017. Service transitions of product-centric firms: An explorative study of service transition stages and barriers in Germany's energy market. International Journal of Production Economics.

MARCH, J. G. 1991. Exploration and exploitation in organizational learning. Organization Science, 2, 71-87.

MARTIN, P. C. G., SCHROEDER, A. \& BIGDELI, A. Z. 2019. The value architecture of servitization: Expanding the research scope. Journal of Business Research.

MARTINEZ, V., BASTL, M., KINGSTON, J. \& EVANS, S. 2010. Challenges in transforming manufacturing organisations into product-service providers. Journal of Manufacturing Technology Management, 21, 449-469.

MARTINEZ, V., NEELY, A., VELU, C., LEINSTER-EVANS, S. \& BISESSAR, D. 2017. Exploring the journey to services. International Journal of Production Economics, 192, 66-80.

MEIJERING, J. V., KAMPEN, J. K. \& TOBI, H. 2013. Quantifying the development of agreement among experts in Delphi studies. Technological Forecasting and Social Change, 80, 1607-1614.

MENNENS, K., VAN GILS, A., ODEKERKEN-SCHRÖDER, G. \& LETTERIE, W. 2018. Exploring antecedents of service innovation performance in manufacturing SMEs. International Small Business Journal, 36, 500-520.

MENOR, L. J., TATIKONDA, M. V. \& SAMPSON, S. E. 2002. New service development: Areas for exploitation and exploration. Journal of Operations Management, 20, 135157.

MEYER, A. D., BROOKS, G. R. \& GOES, J. B. 1990. Environmental jolts and industry revolutions : Organizational responses to discontinuous change. Strategic Management Journal, 11, 93-110.

MEYER, A. D., GOES, J. B., BROOKS, G. R. \& HUBER, G. 1995. Organizations reacting to hyperturbulence. Longitudinal Field Research Methods: Studying Processes in Organizational Change, 66-111.

MEYER, J. W. \& ROWAN, B. 1977. Institutionalized organizations: Formal structure as myth and ceremony. American Journal of Sociology, 83, 340-363. 
MITROFF, I. I. \& TUROFF, M. 2002. Philosophical and methodological foundations of Delphi. In: LINSTONE, H. A. \& TUROFF, M. (eds.) The Delphi method: Techniques and applications. London: Addison-Wesley.

MOORE, C. M. 1987. Group techniques for idea building, Sage Publications, Inc.

MULLEN, P. M. 2003. Delphi: myths and reality. Journal of Health Organization and Management, 17, 37-52.

NEELY, A. 2008. Exploring the financial consequences of the servitization of manufacturing. Operations Management Research, 1, 103-118.

NG, I., PARRY, G., SMITH, L., MAULL, R. \& BRISCOE, G. 2012. Transitioning from a goods-dominant to a service-dominant logic: Visualising the value proposition of RollsRoyce. Journal of Service Management, 23, 416-439.

OLIVA, R., GEBAUER, H. \& BRANN, J. M. 2012. Separate or integrate? Assessing the impact of separation between product and service business on service performance in product manufacturing firms. Journal of Business-to-Business Marketing, 19, 309-334.

OLIVA, R. \& KALLENBERG, R. 2003. Managing the transition from products to services. Internation Journal of Service Industry Management, 14, 160-172.

OPRESNIK, D. \& TAISCH, M. 2015. The value of Big Data in servitization. International Journal of Production Economics, 165, 174-184.

PAIOLA, M., SACCANI, N., PERONA, M. \& GEBAUER, H. 2013. Moving from products to solutions: Strategic approaches for developing capabilities. European Management Journal, 31, 390-409.

PARÉ, G., TRUDEL, M. C., JAANA, M. \& KITSIOU, S. 2015. Synthesizing information systems knowledge: A typology of literature reviews. Information and Management, 52, 183-199.

PARIDA, V., SJÖDIN, D. R., WINCENT, J. \& KOHTAMÄKI, M. 2014. Mastering the transition to product-service provision: Insights into business models, learning activities, and capabilities. Research Technology Management, 57, 44-52.

PARKER, A. \& TRITTER, J. 2006. Focus group method and methodology: Current practice and recent debate. International Journal of Research \& Method in Education, 29, 2337.

PARRY, G. C., BRAX, S. A., MAULL, R. S. \& NG, I. C. 2016. Operationalising IoT for reverse supply: The development of use-visibility measures. Supply Chain Management: An International Journal, 21, 228-244.

PEARCE, J. A., CHAPMAN, B. L. \& DAVID, F. R. 1982. Environmental scanning for small and growing firms. Journal of Small Business Management, 20, 27-34.

PEILlON, S., PELLEGRIN, C. \& BURLAT, P. 2015. Exploring the servitization path: A conceptual framework and a case study from the capital goods industry. Production Planning \& Control, 7287, 1-14.

PETTIGREW, A. M. 1985. Contextualist research and the study of organizational change processes. Doing Research that is Useful in Theory and Practice, 222-273.

PETTIGREW, A. M. 1987. Context and action in the transformation of the firm. Journal of Management Studies, 24, 649-670.

PETTIGREW, A. M. 2012. Context and action in the transformation of the firm: A reprise. Journal of Management Studies, 49, 1304-1328.

PFEIFER, J. \& SALANCIK, G. 1978. The external control of companies: A resource dependence perspective. Harper \& Row, New York, NY.

PRAHALAD, C. K. \& RAMASWAMY, V. 2000. Co-opting customer competence. Harvard Business Review, 78, 79-90.

RABETINO, R., KOHTAMÄKI, M. \& GEBAUER, H. 2016. Strategy map of servitization. International Journal of Production Economics, 1-14. 
RADDATS, C., BAINES, T., BURTON, J., STORY, V. M. \& ZOLKIEWSKI, J. 2016. Motivations for servitization: The impact of product complexity. International Journal of Operations \& Production Management, 36, 572-591.

RADDATS, C., BURTON, J. \& ASHMAN, R. 2015. Resource configurations for services success in manufacturing companies. Journal of Service Management, 26, 97-116.

RAJA, J. Z., BOURNE, D., GOFFIN, K., ÇAKKOL, M. \& MARTINEZ, V. 2013. Achieving customer satisfaction through integrated products and services: An exploratory study. Journal of Product Innovation Management, 30, 1128-1144.

RAJA, J. Z., GREEN, S. D. \& LEIRINGER, R. 2010. Concurrent and disconnected change programmes: Strategies in support of servitization and the implementation of business partnering. Human Resource Management Journal, 20, 258-276.

RAPACCINI, M. 2015. Pricing strategies of service offerings in manufacturing companies: A literature review and empirical investigation. Production Planning \& Control, 26, 1247-1263.

REIM, W., PARIDA, V. \& ÖRTQVIST, D. 2015. Product-Service Systems (PSS) business models and tactics - A systematic literature review. Journal of Cleaner Production, 97, 61-75.

REIM, W., PARIDA, V. \& SJÖDIN, D. R. 2016. Risk management for product-service system operation. International Journal of Operations \& Production Management, 36, 665686.

ROEHRICH, J. K. \& LEWIS, M. A. 2010. Towards a model of governance in complex (product-service) inter-organizational systems. Construction Management and Economics, 28, 1155-1164.

ROWE, G. \& WRIGHT, G. 1999. The Delphi technique as a forecasting tool: Issues and analysis. International Journal of Forecasting, 15, 353-375.

ROWE, G. \& WRIGHT, G. 2011. The Delphi technique: Past, present, and future prospects Introduction to the special issue. Technological Forecasting and Social Change, 78, 1487-1490.

ROWE, G., WRIGHT, G. \& BOLGER, F. 1991. Delphi: A reevaluation of research and theory. Technological Forecasting and Social Change, 39, 235-251.

SCHMENNER, R. W. 2009. Manufacturing, service, and their integration: Some history and theory. International Journal of Operations \& Production Management, 29, 431-443.

SCHROEDER, A., ZIAEE BIGDELI, A., GALERA ZARCOS, C. \& BAINES, T. 2019. Capturing the benefits of industry 4.0: A business network perspective. Production Planning \& Control, 1-17.

SHARMA, P. \& SALVATO, C. 2011. Commentary: Exploiting and exploring new opportunities over life-cycle stages of family firms. Entrepreneurship Theory and Practice, 35, 1199-1205.

SILTALOPPI, J. 2015. Framing service as ideology and practice - Cognitive underpinnings of service transformation in Finland's residential sector. Doctoral dissertation. Retrieved 26/7/2019 from https://aaltodoc.aalto.fi/handle/123456789/18993

SOUSA, R. \& DA SILVEIRA, G. J. 2017. Capability antecedents and performance outcomes of servitization: Differences between basic and advanced services. International Journal of Operations \& Production Management, 37, 444-467.

SPRING, M. \& ARAUJO, L. 2016. Product biographies in servitization and the circular economy. Industrial Marketing Management, 1-33.

STORBACKA, K., WINDAHL, C., NENONEN, S. \& SALONEN, A. 2013. Solution business models: Transformation along four continua. Industrial Marketing Management, 42, 705-716. 
STORY, V. M., RADDATS, C., BURTON, J., ZOLKIEWSKI, J. \& BAINES, T. 2017. Capabilities for advanced services: A multi-actor perspective. Industrial Marketing Management, 60, 54-68.

TUROFF, M. 1970. The design of a policy Delphi. Technological Forecasting and Social Change, 2, 149-171.

TURUNEN, T. \& FINNE, M. 2014. The organisational environment's impact on the servitization of manufacturers. European Management Journal, 32, 603-615.

TUSHMAN, M. L. \& ANDERSON, P. 1986. Technological discontinuities and organizational environments. Administrative Science Quarterly, 439-465.

ULAGA, W. \& REINARTZ, W. J. 2011. Hybrid offerings: How manufacturing firms combine goods and services successfully. Journal of Marketing, 75, 5-23.

VALTAKOSKI, A. 2017. Explaining servitization failure and deservitization: A knowledgebased perspective. Industrial Marketing Management, 60, 138-150.

VALTAKOSKI, A. \& WITELL, L. 2018. Service capabilities and servitized SME performance: Contingency on firm age. International Journal of Operations \& Production Management, 38, 1144-1164.

VAN DE VEN, A. \& DELBECQ, A. L. 1971. Nominal versus interacting group processes for committee decision-making effectiveness. Academy of Management Journal, 14, 203212.

VAN DE VEN, A. \& POOLE, S. 1995. Explaining development and change in organizations. Academy of Management Review, 20, 510-540.

VAN DE VEN, A. H. \& DELBECQ, A. L. 1972. The nominal group as a research instrument for exploratory health studies. American Journal of Public Health, 62, 337-342.

VAN DE VEN, A. H. \& DELBECQ, A. L. 1974. The effectiveness of nominal, Delphi, and interacting group decision-making processes. Academy of Management Journal, 17, 605-621.

VIDGEN, R., SHAW, S. \& GRANT, D. B. 2017. Management challenges in creating value from business analytics. European Journal of Operational Research, 261, 626-639.

VISNJIC, I., WIENGARTEN, F. \& NEELY, A. 2016. Only the brave: Product innovation, service business model innovation, and their impact on performance. Journal of Product Innovation Management, 33, 36-52.

VISNJIC KASTALLI, I. \& VAN LOOY, B. 2013. Servitization: Disentangling the impact of service business model innovation on manufacturing firm performance. Journal of Operations Management, 31, 169-180.

WEICK, K. E. \& QUINN, R. E. 1999. Organizational change and development. Annual Review of Psychology, 50, 361-86.

WINDAHL, C. \& LAKEMOND, N. 2006. Developing integrated solutions: The importance of relationships within the network. Industrial Marketing Management, 35, 806-818.

WINDAHL, C. \& LAKEMOND, N. 2010. Integrated solutions from a service-centered perspective: Applicability and limitations in the capital goods industry. Industrial Marketing Management, 39, 1278-1290.

WINDLER, K., JÜTTNER, U., MICHEL, S., MAKLAN, S. \& MACDONALD, E. K. 2017. Identifying the right solution customers: A managerial methodology. Industrial Marketing Management, 60, 173-186.

WOUDENBERG, F. 1991. An evaluation of Delphi. Technological Forecasting and Social Change, 40, 131-150.

XIAO, J., DOUGLAS, D., LEE, A. H. \& VEMURI, S. R. 1997. A Delphi evaluation of the factors influencing length of stay in Australian hospitals. The International Journal of Health Planning and Management, 12, 207-218. 
XING, Y., LIU, Y., TARBA, S. \& COOPER, C. L. 2017. Servitization in mergers and acquisitions: Manufacturing firms venturing from emerging markets into advanced economies. International Journal of Production Economics, 192, 9-18.

YALCINKAYA, G., CALANTONE, R. J. \& GRIFFITH, D. A. 2007. An examination of exploration and exploitation capabilities: Implications for product innovation and market performance. Journal of International Marketing, 15, 63-93.

ZIAEE BIGDELI, A. \& BAINES, T. 2017. Organisational change towards servitization: A theoretical framework. Proceedings of the Spring Servitization Conference: Internationalisation through Servitization.

ZIAEE BIGDELI, A., BAINES, T., SCHROEDER, A., BROWN, S., MUSSON, E., GUANG SHI, V. \& CALABRESE, A. 2018. Measuring servitization progress and outcome: The case of 'advanced services'. Production Planning \& Control, 29, 315-332. 